Artículo de Investigación

\title{
Finanzas públicas y desigualdad fiscal en los municipios de Boyacá, 1985 2010*
}

\author{
Public finance and taxation inequality in the \\ municipalities of Boyacá, 1985 2010
}

Plinio Atanael Guerrero Guerrero**

Fecha de recepción: 20 de agosto de 2013

Concepto de evaluación: 6 de febrero de 2014

Fecha de aprobación: 21 de marzo de 2014

\footnotetext{
Este artículo es resultado del trabajo de investigación como docente de primer nombramiento, de acuerdo con la normatividad de la Universidad Pedagógica y Tecnológica de Colombia. Agradezco los comentarios de los jurados evaluadores internos en relación con el trabajo de investigación, lo mismo que de los evaluadores anónimos del artículo.

** Magíster en Economía, especialista en Gestión de Proyectos, docente de la Escuela de Economía de la Universidad Pedagógica y Tecnológica de Colombia. Catedrático de la ESAP, Tunja, Boyacá, Colombia. Correo electrónico: plinio.guerero@uptc.edu.co
} 


\section{Resumen}

La desigualdad de los ingresos fiscales per cápita de los municipios y provincias del departamento de Boyacá y su evolución, es analizada utilizando tres indicadores (Gini, Theil y coeficiente sigma), para acercarse a la explicación de la contribución del proceso de descentralización fiscal en la reducción de las disparidades intermunicipales y provinciales. De los resultados obtenidos, se deduce que en materia fiscal hay un proceso de convergencia, además, al contrastarlos con indicadores como el NBI, el porcentaje de población en situación de pobreza y el Gini de gastos por municipio, en 1993 y 2005, estos últimos presentan disminuciones importantes que en cierta forma corroboran la mejora en los indicadores de equidad.

Palabras clave: descentralización fiscal, finanzas públicas, ingresos fiscales, convergencia, indicadores de desigualdad, Gini, Theil y coeficiente sigma.

JEL: H21, C43, D63, H77, H79

\section{Abstract}

Inequality in tax revenue per capita for municipalities and provinces of the department of Boyacá and its evolution, is analyzed using three indicators (Gini, Theil and sigma factor), for approaching to the explanation of the contribution of taxation decentralization process in the reduction of inter municipal and provincial disparities. The results suggest that in tax matters there is a process of convergence, moreover, to contrast them with indicators such as the NBI, the percentage of population in poverty and the Gini expenditure by municipality, in 1993 and 2005, the latter presented important decreases that somehow confirm the improvement in the taxation equity indicators.

Keywords: taxation decentralization, public finance, tax revenue, convergence, inequality indicators, Gini, Theil and sigma factor. 


\section{INTRODUCCIÓN}

El tema de la distribución de las rentas y, a través de ellas, el de los bienes y servicios de consumo final, ocupa un interés especial en la literatura económica desde los mismos clásicos (Smith y Ricardo). Igualmente, las controversias en torno al papel que deben jugar el mercado y el Estado sobre el tema aludido y si la función de este último debe efectuarse desde el nivel central o es mejor actuar en forma descentralizada. Finalmente, y después de muchos años de centralismo, existe acuerdo en cuanto a la necesidad de otorgar un mayor grado de autonomía tanto a las regiones como a las localidades, por lo que la descentralización constituye una parte importante de los procesos de reforma del Estado implementados durante las últimas cuatro décadas; empero, las discrepancias giran en torno al cómo y a la finalidad de las decisiones.
Uno de los propósitos de los procesos de descentralización pública, desde el punto de vista gubernamental, fue el de contribuir a la equidad, pues desde sus inicios se reconocía que existían problemas de desigualdad entre las diferentes regiones y localidades, al punto que el principio de igualdad en dichos procesos quedó consignado constitucionalmente, no obstante, en la práctica prevalece el eficientismo fiscal.

En diferentes estudios realizados a nivel departamental se concluye que el proceso no ha logrado el objetivo propuesto y que, por el contrario, se han ahondado las disparidades existentes, mientras que para otros la política de descentralización $y$ de transferencias ha sido efectiva y ha contribuido a mejorar la distribución del ingreso promedio. El número de investigaciones realizadas, dedicadas a refutar la conclusión de convergencia, parece estar en favor de los primeros. 
Para aportar en el análisis de la problemática aludida, en este trabajo se busca determinar si los procesos de descentralización fiscal, adelantados desde la década de los ochenta del siglo $\mathrm{XX}$, han contribuido a mejorar los indicadores de equidad fiscal, entre los diferentes municipios y provincias del departamento de Boyacá, a partir del análisis de las cifras de las ejecuciones presupuestales municipales desde 1985 a 2010, con el ánimo de encontrar evidencia que ratifique o desmienta las conclusiones contradictorias antes referidas.

Se han seleccionado los ingresos fiscales, porque las dinámicas tanto de las estructuras tributarias como de las estructuras productivas, están estrechamente vinculadas y además porque los impuestos de la propiedad municipal (predial), y los ingresos de industria y comercio (ICA), de algún modo reflejan la riqueza y el nivel de actividad y desarrollo económico de un municipio (Núñez \& Sánchez, 2000).

Para ello se construyeron varios índices de equidad que permiten establecer el comportamiento de los principales ingresos fiscales, a lo largo del período analizado. Concretamente, se emplearon tres indicadores de equidad: el Theil, el GINI y el de convergencia sigma $(\sigma)$.

El análisis de los resultados obtenidos con los tres indicadores aludidos, permite identificar comportamientos diferentes para los índices que miden las desigualdades de los ingresos totales y corrientes per cápita y los que miden la inequidad de los ingresos propios (tributarios: predial e ICA y no tributarios). En el primer caso, los índices son relativamente bajos, en tanto que la inequidad de los ingresos propios, es considerable, hecho que permitiría concluir que las transferencias que ha realizado el nivel central, sí han contribuido a reducir la desigualdad entre los municipios, por lo menos en términos fiscales. Además, se deduce que las diferencias que se presentaron en los ingresos propios, en la segunda parte de la década de los noventa del siglo XX, se redujeron en la primera década del presente siglo, al punto que se puede concluir que allí se presenta un proceso de convergencia.

Al contrastar los resultados obtenidos a través de los indicadores mencionados, con algunos indicadores de bienestar como el NBI, el porcentaje de población en situación de pobreza y el Gini de gastos por municipio, elaborados por otros autores y entidades, para los años de 1993 y 2005 , se observa que estos últimos presentan disminuciones importantes que corrobaran en cierta forma la mejora en los indicadores de equidad. Sin embargo, estos resultados deben tomarse con precaución, pues la reducción no necesariamente implica mejoría en las condiciones económicas de los municipios de menor desarrollo, y, más bien, es consecuencia del esfuerzo fiscal realizado por todas las administraciones municipales. 
Para el logro del objetivo propuesto, el trabajo se compone de tres partes. La primera conformada por esta introducción; a continuación se examinan de forma sucinta los principios teóricos que le sirve de referencia analítica, en tercer lugar se presentan los resultados del trabajo, dividido a su vez en dos secciones: en la primera aparece el análisis de los indicadores de equidad de varios ingresos per cápita y a continuación se presentan las disparidades intra e interprovincias de Boyacá. Por último se elaboran unas conclusiones.

El trabajo se realiza en un horizonte de largo plazo porque en la revisión bibliográfica solamente se encontraron estudios que no van más allá de unos pocos años, descuidando el análisis de tendencias de largo plazo, y además, porque los análisis de convergencia se hacen a largo plazo.

\section{NUEVO MODELO DE DESARRO-} LLO, REFORMAS ESTATALES, DESCENTRALIZACIÓN PÚBLICA Y EQUIDAD DISTRIBUTIVA

Durante las tres últimas décadas del siglo $\mathrm{XX}$ y en lo corrido del presente, en el marco del modelo de apertura económica, se han adelantado diferentes reformas del Estado en la mayor parte de los países, entre las que se incluye la descentralización pública ${ }^{1}$ como uno de los componentes más importantes de tales reformas, encaminadas a darle una mayor prelación a los principios del mercado. En casi todos los trabajos relacionados con el análisis de los procesos de descentralización pública, se menciona que uno de los propósitos de tal medida, desde el punto de vista gubernamental, es contribuir a la equidad, pues se reconoce que existen problemas de desigualdad entre las diferentes regiones y localidades.

Así mismo, el Estado en el nivel central, de acuerdo con Musgrave \& Musgrave (1992), conserva la función de redistribución de ingresos teniendo presente el criterio de equidad, pues se supone, como lo hace Prud'homm (1995) citado por Bonet 2004), que los presupuestos nacionales juegan un papel importante en la reducción de disparidades regionales.

En el artículo 209 de la Constitución Política de 1991, se plantean los principios de la función administrativa así: "igualdad, moralidad, eficacia, economía, celeridad, imparcialidad y publicidad, mediante $l a$ descentralización, la delegación y la desconcentración de funciones" ${ }^{2}$.

Si bien es cierto, el principio de equidad sirve de fundamento al proceso de

\footnotetext{
Tiene tres componentes: administrativo, fiscal y político, los cuales se implementan en diferentes momentos dependiendo de las circunstancias.

2 Que se puede constatar en http://pdba.georgetown.edu/Constitutions/Colombia/colombia91.pdf
} 
descentralización, en el país se ha dado prevalencia a la eficiencia del gasto, a la transparencia y a la legalidad, y de acuerdo con Shah, (2005, p. 30)

A pesar de los graves desequilibrios fiscales horizontales en un gran número de países en desarrollo, (...) los mecanismos diseñados e implementados para el cálculo de los ingresos que se transfieren, combinan objetivos diversos y contradictorios en la misma fórmula, por lo que se fracasa al tratar de abordar los objetivos de equidad regional sin hacer explícitos los estándares de igualación.

Por otra parte, en varios escritos se concluye que el proceso no ha logrado el objetivo propuesto y que, por el contrario, las transferencias del orden nacional, hoy sistema general de participaciones-SGP, han contribuido a ahondar las disparidades existentes. Así lo sostiene Martínez (2006, p. 4), quien afirma que "...para datos recientes o al menos, durante los años noventa, el consenso apunta a que no ha habido convergencia, y por el contrario, se ha presentado una polarización en los ingresos per cápita. En otras palabras, ha aumentado la brecha entre regiones ricas y pobres." Lo anterior conduciría a una situación ya anunciada por Betancurt et al. (2002, p. 69) quienes señalan que “...el desplazamiento del énfasis en la equidad que estaba en la Ley 60 de 1993 por el de la eficiencia, no promete el mejor impacto sobre el acceso a los servicios sociales básicos y a la protección social de los más pobres y otras poblaciones vulnerables...".

E1 tema reviste una importancia particular, por cuanto en los estudios realizados a nivel departamental por el CEGA, en cabeza del profesor Luis Lorente (2006), por una parte, y por la otra, Bonet y Meisel (2007) y Bonet (2004), las conclusiones resultan contradictorias, ya que en el primer caso la política de descentralización y de transferencias ha sido efectiva y ha contribuido a mejorar la distribución del ingreso promedio, mientras que para los segundos la descentralización fiscal no ha favorecido la reducción de las disparidades regionales y más bien ha tendido a aumentarlas, por lo que sería necesario establecer una política de Estado orientada a reducir las enormes diferencias en los ingresos per cápita de sus entes territoriales.

Además, porque en términos generales, “...las disparidades internas de las regiones dificultan el crecimiento sostenido y equilibrado de las mismas, obstaculizando la posible convergencia entre regiones ricas o prósperas y regiones pobres o débiles" y porque “...la evidencia empírica sobre el proceso de crecimiento económico demuestra que la desigualdad en la distribución de la renta en el interior de un territorio reduce su crecimiento" (Rupasingha et al., 2002, p. 153, citados por Peña, A. 2004, p. 2), empeorando la situación en vez de mejorarla como se dijo inicialmente. 
Puesto que las dinámicas, tanto de las estructuras tributarias como de las estructuras productivas, están estrechamente vinculadas, es apenas lógico encontrar diferencias en los niveles de producción y como consecuencia “...una gran desigualdad en los ingresos fiscales per cápita de los entes territoriales, lo cual implica que éstos asumen la responsabilidad de prestación de servicios en condiciones muy diferentes." (Bonet 2004, p. 1) y si además se tiene presente que “...las pequeñas diferencias en las tasas de crecimiento del ingreso per cápita generan grandes diferencias en los niveles de ingreso per cápita de largo plazo" (Sala-I-Martin, 1999, p. 6), entonces la situación en términos de inequidad intra e interregional tiende a profundizarse.

Las causas que explican las diferencias, están asociadas a las disparidades que se presentan históricamente entre las estructuras productivas de las regiones y subregiones; por cuanto están provistas de recursos naturales en diversas proporciones, en términos de calidad y cantidad $^{3}$. También por localización en relación con los grandes centros de consumo, por extensión y calidad del suelo (fertilidad) y subsuelo, topografía, disponibilidad y calidad de recursos hídricos, flora y fauna, recursos humanos, recursos físicos o de infraestructura, maquinarias y equipos, recursos científicos, técnicos y tecnológicos y por ende, capacidades para generar los excedentes necesarios que definen así mismo, asimetrías de las entidades territoriales en cuanto a los niveles de acumulación del capital requerido en aras del crecimiento económico y el desarrollo.

A lo anterior se suman las diferencias culturales, que determinan las instituciones en términos de creencias, instituciones (normas y reglas) que permiten el desarrollo de las funciones y estructuras organizacionales e inciden en el ritmo de crecimiento y en últimas en el desarrollo económico, hasta el punto que, como lo señala Vázquez Barquero (1999a, pág. 243, citado por Peña, A. 2004, p. 2),

...uno de los factores que han contribuido al desarrollo de la estrategia de crecimiento endógeno durante las dos últimas décadas en los países europeos ha sido el aumento y mejora de la red de instituciones locales y, sobre todo, el cambio de las formas de organización del Estado hacia modelos que favorecen los procesos de descentralización administrativa.

Los altos índices tanto de pobreza como de desigualdad de los ingresos, demuestran la problemática social de una región en materia de distribución de la

$3 \quad$ Las variables geográficas explican el $24 \%$ de la variación del ingreso per cápita en los municipios pobres y $19 \%$ en los más ricos (Núñez \& Sánchez, 2000, p. 21). 
renta y en consecuencia del producto. En todos los gobiernos uno de los objetivos clave de la política social es el de la reducción de la pobreza, para lo cual se han implementado diferentes programas que han bajado los índices ${ }^{4}$, a pesar de lo cual 800 municipios tenían un índice de pobreza superior al $66 \%$. No obstante, para mejorar los índices de distribución del ingreso no es mucho lo que se hace, pues la desigualdad se mantiene, al punto de ubicar a Colombia como el país más desigual de América Latina y el cuarto en el mundo ${ }^{5}$. Parece que el modelo de desarrollo implementado desde la década de los noventa ha hecho que Colombia tenga ingresos más altos sin que se logre una mejor distribución.

Siguiendo a Debraj (2000) y a Marx (1859), la distribución de la renta y en consecuencia de los bienes y servicios de consumo final, está directamente relacionada con la distribución de los recursos que la generan ${ }^{6}$, de modo que la determinación de la proporción por recibir, dependerá de la forma como cada individuo u hogar participe en la distribución de tales recursos y esto a su vez depende en parte de condiciones históricas y geográficas. Las políticas públicas pueden afectar la distribución del ingreso determinada en el ámbito privado (por el mercado), ya sea a través de cambios en la distribución de recursos o a través de una redistribución del ingreso.

Con suficiente voluntad política, los gobiernos pueden abordar las condiciones para superar o para perpetuar la desigualdad, mediante la implementación de políticas apropiadas. Como se sabe, la política tributaria contribuye a mejorar los índices de equidad con un sistema tributario progresivo, pero, además, el objetivo también se puede lograr con la implementación de los mecanismos necesarios para el cálculo de los ingresos que se transfieren desde el nivel central a las regiones o a los municipios, explicitando el objetivo de equidad regional.

Puesto que desde el inicio de este documento se ha venido hablando de equidad, con el convencimiento de que el significado es de dominio común, es necesario abordar brevemente el alcance del mismo, labor que se adelanta a continuación.

4 "Entre 2002 y 2010, el porcentaje de pobres disminuyó (...) la incidencia pasó de 49,4 \% a 37,2 \%. En números absolutos, significa que en el 2002 había 19.835 .029 personas pobres y en el 2010 había 16.432 .158 . Ello significa que en este período 3.402.871 de personas salieron de la pobreza. "Ver artículo de Jorge Iván González (2006) "La pobreza disminuye pero las brechas aumentan", publicado en http://razonpublica.com/index.php/ component/content/article/167-articulos-recientes-/2369-la-pobrezadisminuyeperolas-brechas-aumentan.html. Debe aclararse que se ha planteado un debate sobre este tema, pues economistas como el profesor Manuel Muñoz cuestionan los resultados por la metodología empleada.

5 "El 10 por ciento más rico de los colombianos, 4,6 millones, posee el $45 \%$ de la riqueza. Si le sumamos a los segundos más ricos, en total 9 millones, ambos concentran el $61 \%$ de la riqueza. Y esto quiere decir que los 37 millones de colombianos restantes solo tienen acceso al 39 \% de la riqueza." (Bonilla, 2011).

6 Corresponden a los llamados retornos factoriales desde la óptica neoclásica. 


\section{Breves consideraciones sobre el concepto de equidad}

Tal como lo hacen notar González (2006) y Thurrow (1973), no es fácil precisar el significado del concepto de equidad ${ }^{7}$, a pesar de lo cual, aquí se tratará de realizar un acercamiento al mismo.

El término viene del latín aequitas, de aequus, que significa igual ${ }^{8}$, o criterio que orienta la distribución de un determinado atributo entre los miembros de un grupo social. Los atributos se refieren a la riqueza, a los recursos productivos, al ingreso, al consumo o nivel de gasto y últimamente, a las oportunidades.

El concepto de equidad, como lo resalta Tiana (2010), matiza el contenido ideológico del concepto de igualdad en las sociedades capitalistas, pues el primero es un concepto más neutral que el segundo, sin que se desvinculen totalmente, ya que al hacer referencia a la equidad no se puede eludir la pregunta formulada por Sen (1992) sobre este particular: "Igualdad ¿de qué?", interrogante que lo conduce a plantear la existencia de varias dimensiones de la igualdad: de recursos, de ingresos y de oportunidades. Por ello, como lo anota
González (2006), tanto para Sen como para Arrow, la equidad se basa en la justicia redistributiva, hasta el punto de llegar a replantear las asignaciones iniciales, labor que caería bajo la responsabilidad del Estado. Para el caso, corresponde a la redistribución de ingresos o transferencias desde el nivel nacional hacia las localidades.

Ante las limitaciones que se tienen a nivel municipal para calcular o medir la renta factorial, o los recursos que la posibilitan, en el presente trabajo se ha decidido emplear los ingresos per cápita (totales, corrientes, tributarios, industria y comercio y predial) $)^{9}$ para verificar la siguiente hipótesis de trabajo: El proceso de descentralización fiscal, adelantado desde la década de los ochenta del siglo $\mathrm{XX}$, si bien han contribuido a mejorar los indicadores de equidad a nivel fiscal, entre las diferentes provincias y municipios del departamento de Boyacá, no ha logrado reducir la brecha que se presenta entre provincias y municipios.

La utilización de los ingresos fiscales expresados como indicadores promedio o per cápita, asocia el ingreso fiscal correspondiente con la totalidad de individuos de un municipio, y determina cuánto le corresponde en promedio a

\footnotetext{
En realidad, González hace referencia a los significados tanto de eficiencia como de equidad y aclara que el significado de equidad es todavía menos preciso que el de eficiencia. Thurrow (1973, p. 56 -80) manifiesta que "El desafío de entregar un contenido más o menos concreto y más o menos exacto de la noción de equidad económica podrá haber sido motivo de muchas dificultades, de muchos esfuerzos frustrados y de muchas renuncias incluso, pero permanece tan vigente como siempre”. Así mismo que "...precisar el concepto de equidad económica simplemente constituye un tema difícil para el cual se carece de una respuesta universal".

8 En http://es.wikipedia.org/wiki/Equidad y en concordancia con la Real Academia Española.

9 A partir de las cifras fiscales de los municipios que publica el DNP por clasificación económica.
} 
cada persona ${ }^{10}$. Aunque no es la mejor medida de distribución del ingreso, la relación per-cápita admite comparaciones de los ingresos fiscales entre los municipios en un período de tiempo, y facilita obtener unidades comunes de medida, con las cuales se pueden hacer esas comparaciones. Igualmente, permite visualizar el comportamiento de la variable a lo largo del tiempo, e identificar las diferencias entre los municipios. Y además porque, en palabras de Debraj (2000, p. 120), "Las rentas per cápita bajas constituyen una importante característica del subdesarrollo económico -quizá la más importante-...", de modo que su identificación ayudará a implementar las medidas necesarias para mejorarlas.

Dentro de este marco, se busca analizar la desigualdad fiscal intermunicipal e interprovincial en el departamento de Boyacá, medida a través de tres indicadores: Theil, de GINI, y el de convergencia sigma $(\sigma)$, los cuales se especifican con mayor detalle en el anexo metodológico.

\section{METODOLOGÍA}

La metodología que se emplea se basa en las estadísticas que maneja el DNP, construidas a partir de la información registrada en las ejecuciones presupuestales reportadas al Banco de la República, la Contraloría General de la República y el Ministerio de Hacienda. Para ello se deflactaron las cifras, de modo que el análisis realizado corresponde a los valores reales a precios del año 2008. A continuación y con base en los ingresos fiscales de los municipios de Boyacá se calculan los ingresos per cápita (totales, corrientes, tributarios, industria y comercio y predial), a partir de los cuales se construyen varios índices que permiten establecer el comportamiento en términos de equidad de dichas variables.

Cuando se emplean índices de medición, se debe tener en claro qué es lo que se va a medir, y en este caso corresponde a la equidad o desigualdad entre los municipios del departamento de Boyacá en un momento del tiempo (1985-2010), vista a través del análisis de las finanzas municipales; así mismo cómo se va a medir o qué indicadores se van a emplear para determinar la inequidad en la distribución de los ingresos que mide el indicador. El análisis del comportamiento de los indicadores obtenidos para un momento del tiempo (un año), a lo largo de un período de tiempo, permite deducir si la desigualdad aumenta o se reduce.

En este trabajo se emplearon tres medidas de desproporcionalidad $^{11}$, o

\footnotetext{
$\overline{10}$ También se puede interpretar como la carga tributaria per cápita, la cual se define como el valor promedio de lo que correspondería pagar en tributos a cada habitante, si existiese una equidistribución de las cargas tributarias entre toda la población de un municipio o departamento. Relaciona el total de ingresos tributarios, dividido entre la población del ente analizado (DNP, 2008, p. 37).

11 Un índice de desigualdad es una medida que resume la manera como se distribuye una variable entre un conjunto
} de individuos. 
indicadores de equidad: los índices de Theil, de GINI y el de convergencia sigma $(\sigma)$. Igualmente, se analizan el NBI, el nivel de pobreza y el GINI de gastos para los años 1993 y 2005, con el fin de verificar si se han presentados mejoras o por el contrario, si los niveles de desigualdad se han incrementado.

\section{Índice de Theil}

Este índice, aunque se utiliza con menos frecuencia que el coeficiente de Gini, tiene la ventaja que con él se puede calcular la parte de la desigualdad que cada uno de los diferentes subgrupos o regiones de análisis, hace a la desigualdad total.

En el primer caso (índice de Theil), si el rubro de los ingresos fiscales per cápita seleccionado se encuentra equitativamente distribuido dentro de los municipios del departamento, no hay desigualdades y el coeficiente es cero (0) y al contrario.

$$
T=\sum x_{i} \ln \left(x_{i} n\right)
$$

donde $\mathrm{n}$ toma el valor 123 y $x_{i} n$ son las participaciones de cada municipio en el ingreso total. Así mismo, para calcular las desigualdades intra e inter provincias, se tuvo en cuenta la siguiente expresión:

$$
T_{1}+T_{2}=\sum_{j} v_{j} \sum_{i j} \ln \left(x_{i j} n_{j}\right)+\sum_{j} v_{j} \ln \left(v_{j} n / n_{j}\right)
$$

La primera parte mide la desigualdad dentro de las provincias y la segunda las desigualdades entre las provincias (Lora,
2009, p. 78).

De acuerdo con Firebaugh (citado por Bacallao, 2007, p. 10), el índice de Theil puede transformarse de modo que tome valores en el intervalo $(0,1)$, así:

$$
Z_{T}=1-\exp (-T)
$$

El valor mínimo de cero (0) corresponde al caso en que $s_{i}=n_{i}$ para todo i, es decir cuando, para todos los municipios el ingreso per cápita seleccionado en relación con el ingreso per cápita total es igual a la proporción poblacional, o al número total de municipios. El valor máximo (uno=1) se alcanza sólo como valor límite cuando las medidas no transformadas de los índices tienden a $+\infty$.

\section{Índice de convergencia sigma $(\sigma)$}

Es una medida de dispersión que indica el grado de desigualdad existente entre diferentes municipios, con referencia a una variable previamente especificada. De la igualdad plena en la distribución de la variable per cápita entre los municipios, resultaría una desviación estándar de cero, mientras que a mayor desigualdad, corresponde una mayor desviación estándar. Por otra parte, si la dispersión entre los municipios de la variable seleccionada, tiende a reducirse en el tiempo, existe una tendencia a que se presente la llamada convergencia sigma.

La convergencia sigma se define como la evolución en el periodo de tiempo 
considerado de la desviación estándar del fórmula utilizada para cualquiera de los logaritmo de la variable elegida y la ingresos tributarios per cápita es:

Desviación Estándar de los Logaritmos $(\mathrm{DEL})^{12}=\sigma_{t}=\sqrt{\frac{\sum_{i=1}^{N}\left(\ln \operatorname{Ing} \operatorname{Tribp}_{i t}-\ln \operatorname{Ing} \operatorname{Tribp}_{\mathrm{t}}\right)^{2}}{N}}$

Donde $\ln \operatorname{IngTribpc}_{i t}$ es el logaritmo natural del ingreso tributario per cápita del municipio "i" en el año "t", "ln IngTribpc" es el logaritmo natural de la media de cada uno de los ingresos tributarios per cápita de los municipios y "N" corresponde al número de los municipios (123) del departamento de Boyacá (Márquez, 2011, p. 33).

\section{Índice de Gini}

El coeficiente de concentración de Gini es uno de los índices que ha tenido mayor aceptación en los trabajos empíricos y el más utilizado en el estudio de la desigualdad de ingresos. Su valor está entre un mínimo de cero $(0)$, que corresponde a una distribución equitativa para cada individuo de la población de la variable seleccionada y un máximo de uno (1), situación que se verifica cuando el individuo $\boldsymbol{n}$ concentra todos los ingresos $\mathrm{Yn}^{13}$.

\section{ANÁLISIS DE RESULTADOS}

Como antes se dijo, para analizar el comportamiento de los ingresos fiscales per cápita de los municipios de Boyacá, en términos de equidad, o verificar si se

12 Según Fernando Medina, "Esta transformación, a diferencia de la varianza y la desviación estándar, tiene la ventaja que elimina los problemas asociados a las unidades de medida. Además, a las transferencias que se realizan en la parte baja de la distribución se les asigna mayor ponderación que a las que se efectúan en los niveles altos de ingreso" (2001, p. 11).

13 "Si se tiene información sobre $n$ individuos ordenados en forma creciente respecto al valor de sus ingresos: y1 $\leq$ y $2, \ldots, \leq$ yn, y además, se construye la distribución de frecuencias relativas simple y acumulada de la población bajo estudio ( $\mathrm{pi}, \mathrm{Pi}$ ), así como de la variable a distribuir. Debido al ordenamiento de los datos, se cumple que $\mathrm{Yi} \leq \mathrm{Yi}+1$. Conforme a lo anterior, el coeficiente de desigualdad de Gini se basa en la suma de las diferencias $(\mathrm{Pi}-\mathrm{Yi})$. Con el propósito de estandarizar su recorrido al intervalo $[0,1]$, la expresión anterior se divide entre $\sum_{i=1}^{i k-1} P_{i}$, dando paso a una de las fórmulas que comúnmente se utilizan para calcular el índice de Gini cuando se dispone de datos no agrupados: $\mathrm{G}=\frac{\sum_{i=1}^{n-1} P_{i}-Y_{i}}{\sum_{i=1}^{n-1} P_{i}} \mathrm{El}$ valor mínimo del indicador es cero, y se obtiene cuando $\mathrm{Pi}=\mathrm{Yi} \forall_{i}$, mientras que asume el valor 1 cuando $\mathrm{Y} 1=\mathrm{Y} 2=\ldots=\mathrm{Yn}-1=0$, ya que en este caso el individuo $\mathrm{n}$ concentra todo el ingreso Yn". (Medina, 2001, p. 11). 
ha presentado convergencia o divergencia, se estimaron tres indicadores usados en los trabajos sobre disparidades en el ingreso: los índices de Theil, de GINI, y el de convergencia sigma $(\sigma)$. Los resultados se analizan en conjunto para el caso de coeficiente de Gini y el índice de Theil, teniendo en cuenta que las diferencias no son significativas, y además por que refuerza, en principio, la calidad de las conclusiones que se extraen de la aplicación de ambos indicadores para medir el grado y evolución de las disparidades.

A continuación se examinan los resultados obtenidos para el caso de la convergencia sigma, medida por la desviación estándar del logaritmo de cada uno de los ingresos fiscales per cápita y, en último término, se analizan los resultados de la medición de la desigualdad intra e interprovincial a través del índice de Theil, el cual permite verificar la contribución de la desigualdad entre los municipios de cada provincia al índice total de Theil y la contribución a la desigualdad total de la desigualdad entre las provincias.

Comportamiento de la desigualdad de los ingresos fiscales medida con el índice de Theil y el coeficiente de Gini

El análisis de los resultados obtenidos tanto para el índice de Theil, como para el coeficiente de Gini, se presenta en la Tabla 1. Una primera aproximación que se puede realizar respecto a las inequidades, es que las diferencias para los ingresos propios (tributarios-predial e ICA y no tributarios), son superiores a las que se observan tanto en los ingresos corrientes como en los ingresos totales per cápita.

Los índices de Theil para estos últimos son iguales hasta 1995, pero a partir de allí el de los ingresos corrientes per cápita aumenta en relación con los totales como consecuencia de las desigualdades en los ingresos tributarios. 
Finanzas públicas y desigualdad fiscal en los municipios de Boyacá, 1985-2010 Plinio A tanael Guerrero Guerrero

Tabla 1. Municipios de Boyacá. Índices de Theil y de Gini de los Ingresos fiscales.

\begin{tabular}{|c|c|c|c|c|c|c|c|c|c|c|c|c|}
\hline \multirow[t]{2}{*}{ Años } & \multicolumn{6}{|c|}{ Índice de Theil } & \multicolumn{6}{|c|}{ Coeficiente de Gini } \\
\hline & $\begin{array}{l}\frac{\mathscr{U}}{\tilde{\sigma}} \\
\stackrel{0}{0}\end{array}$ & 导 & 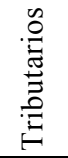 & $\underset{\bigcup}{\circlearrowright}$ & 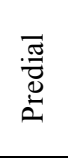 & 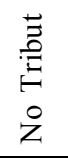 & $\frac{0}{\frac{0}{\pi}}$ & 岕 & 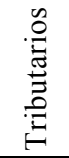 & $\underset{\bigcup}{\circlearrowright}$ & 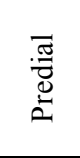 & 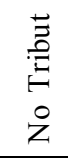 \\
\hline 1985 & 0,13 & 0,13 & 0,67 & 0,74 & 0,42 & 0,53 & 0,24 & 0,24 & 0,54 & 0,73 & 0,43 & 0,53 \\
\hline 1986 & 0,11 & 0,11 & 0,59 & 0,72 & 0,34 & 0,45 & 0,22 & 0,22 & 0,50 & 0,70 & 0,39 & 0,47 \\
\hline 1987 & 0,10 & 0,10 & 0,56 & 0,80 & 0,27 & 0,35 & 0,24 & 0,24 & 0,48 & 0,74 & 0,36 & 0,53 \\
\hline 1988 & 0,12 & 0,12 & 0,45 & 0,77 & 0,35 & 0,50 & 0,25 & 0,25 & 0,47 & 0,74 & 0,44 & 0,52 \\
\hline 1989 & 0,09 & 0,09 & 0,69 & 0,83 & 0,34 & 0,54 & 0,21 & 0,21 & 0,57 & 0,81 & 0,44 & 0,63 \\
\hline 1990 & 0,05 & 0,05 & 0,69 & 0,90 & 0,35 & 0,83 & 0,17 & 0,17 & 0,55 & 0,88 & 0,44 & 0,66 \\
\hline 1991 & 0,04 & 0,04 & 0,62 & 0,88 & 0,30 & 0,87 & 0,15 & 0,15 & 0,53 & 0,87 & 0,42 & 0,66 \\
\hline 1992 & 0,05 & 0,05 & 0,70 & 0,88 & 0,27 & 0,92 & 0,17 & 0,17 & 0,56 & 0,87 & 0,40 & 0,63 \\
\hline 1993 & 0,05 & 0,05 & 0,57 & 0,85 & 0,35 & 0,74 & 0,18 & 0,18 & 0,51 & 0,86 & 0,42 & 0,65 \\
\hline 1994 & 0,07 & 0,07 & 0,40 & 0,84 & 0,22 & 0,86 & 0,19 & 0,20 & 0,44 & 0,86 & 0,37 & 0,66 \\
\hline 1995 & 0,06 & 0,06 & 0,39 & 0,79 & 0,24 & 0,88 & 0,19 & 0,18 & 0,46 & 0,82 & 0,37 & 0,49 \\
\hline 1996 & 0,11 & 0,16 & 0,47 & 0,83 & 0,27 & 0,41 & 0,24 & 0,30 & 0,50 & 0,85 & 0,39 & 0,55 \\
\hline 1997 & 0,11 & 0,15 & 0,51 & 0,79 & 0,31 & 0,55 & 0,25 & 0,29 & 0,53 & 0,82 & 0,41 & 0,55 \\
\hline 1998 & 0,11 & 0,15 & 0,63 & 0,84 & 0,33 & 0,52 & 0,25 & 0,29 & 0,57 & 0,84 & 0,41 & 0,54 \\
\hline 1999 & 0,12 & 0,17 & 0,66 & 0,78 & 0,26 & 0,51 & 0,26 & 0,31 & 0,59 & 0,81 & 0,39 & 0,48 \\
\hline 2000 & 0,12 & 0,18 & 0,48 & 0,80 & 0,29 & 0,45 & 0,28 & 0,31 & 0,51 & 0,82 & 0,40 & 0,61 \\
\hline 2001 & 0,11 & 0,14 & 0,49 & 0,81 & 0,29 & 0,71 & 0,25 & 0,29 & 0,52 & 0,81 & 0,40 & 0,56 \\
\hline 2002 & 0,13 & 0,17 & 0,41 & 0,72 & 0,32 & 0,58 & 0,27 & 0,31 & 0,48 & 0,75 & 0,41 & 0,58 \\
\hline 2003 & 0,11 & 0,12 & 0,45 & 0,77 & 0,33 & 0,62 & 0,26 & 0,27 & 0,49 & 0,77 & 0,42 & 0,48 \\
\hline 2004 & 0,15 & 0,21 & 0,46 & 0,80 & 0,29 & 0,42 & 0,28 & 0,34 & 0,47 & 0,78 & 0,38 & 0,56 \\
\hline 2005 & 0,11 & 0,13 & 0,42 & 0,78 & 0,29 & 0,58 & 0,25 & 0,27 & 0,46 & 0,75 & 0,25 & 0,46 \\
\hline 2006 & 0,12 & 0,15 & 0,44 & 0,76 & 0,28 & 0,39 & 0,26 & 0,30 & 0,47 & 0,74 & 0,39 & 0,44 \\
\hline 2007 & 0,12 & 0,14 & 0,35 & 0,67 & 0,26 & 0,36 & 0,26 & 0,29 & 0,45 & 0,70 & 0,38 & 0,47 \\
\hline 2008 & 0,11 & 0,15 & 0,34 & 0,70 & 0,30 & 0,41 & 0,24 & 0,29 & 0,43 & 0,70 & 0,40 & 0,48 \\
\hline 2009 & 0,10 & 0,13 & 0,32 & 0,68 & 0,29 & 0,45 & 0,23 & 0,27 & 0,41 & 0,68 & 0,40 & 0,45 \\
\hline 2010 & 0,10 & 0,15 & 0,29 & 0,67 & 0,29 & 0,37 & 0,24 & 0,29 & 0,40 & 0,68 & 0,40 & 0,49 \\
\hline
\end{tabular}

Fuente: cálculos del autor con base en las ejecuciones presupuestales del DNP, varios años.

Mientras que el Theil de los ingresos totales per cápita fluctúa entre el $0.11 \mathrm{y}$ el 0.10 , con un máximo de 0.15 en 2004 , y el Gini varía entre el 0.17 y el 0.28 , el de los ingresos corrientes está por encima de los totales desde 1995, con una diferencia promedio de 0.06 , corriendo prácticamente en paralelo en el subperiodo 1995-2010.
En concordancia con la información de la tabla anterior y en relación con los ingresos propios, los dos coeficientes para todo el período indican una tendencia descendente, de lo que se deduce una disminución de las diferencias o de las desigualdades de ingresos fiscales en términos per cápita intermunicipales. A pesar de la irregularidad que presenta el índice de los ingresos 
tributarios per cápita hasta 1999 , en adelante la desigualdad se reduce de 0,66 a 0,29 , es decir una disminución de 37 puntos en diez años. Situación similar se constata con el Gini que pasa de 0.59 de 1999 a 0.29 en el 2010, es decir una reducción de 30 puntos, que en términos de equidad resultan muy significativos.

El índice de Theil para los ingresos per cápita de industria y comercio (ICA), es el que revela el nivel más alto de desigualdad. En el primer quinquenio del período de análisis, aumenta de 0,74 a 0,90 en 1990, y en adelante la tendencia es descendente hasta llegar al 0,67 en el último año, con una reducción de 23 puntos. Es de aclarar que en los primeros años del período de análisis el número de municipios que recaudaba el ICA corresponde solo a la mitad, aumentando alrededor de cien en 1990, y después del año 2000, prácticamente todos empiezan a recaudar dicho impuesto.

Igual ocurre al hacer el análisis de la evolución seguida por el coeficiente de Gini para esta variable que aumenta de 0.73 a 0.88 en 1990, año a partir del cual se denota la tendencia descendente, por arriba de 0.80 durante la década de los noventa hasta llegar al 0.68 , es decir una reducción de 20 puntos durante veinte años, que en términos de inequidad resultan importantes aunque se mantienen en niveles muy altos.

Tabla 2. Municipios de Boyacá. Gini de los ingresos fiscales.

\begin{tabular}{|c|c|c|c|}
\hline & 1985-2010 & 1985-1995 & 1996-2010 \\
\hline Totales & 0.31 & 0.10 & 0.36 \\
Corrientes & 0.21 & 0.12 & 0.36 \\
Tributarios & 0.77 & 0.85 & 0.74 \\
ICA & 0.92 & 0.95 & 0.91 \\
Predial & 0.69 & 0.49 & 0.73 \\
No Tributarios & 0.50 & 0.47 & 0.72 \\
\hline
\end{tabular}

Fuente: cálculos del autor con base en las ejecuciones presupuestales del DNP, varios años.

La tabla anterior muestra la tendencia de dicho indicador aplicado a la media por períodos. En los ingresos totales y corrientes, la desigualdad se incrementa después de 1995, cuando aumenta el volumen de recursos transferidos, lo que induce a pensar que las transferencias, en vez de contribuir a la reducción de la inequidad, la intensificaron. El Gini del ICA se reduce el $4 \%$ en el segundo período incidiendo sobre los ingresos tributarios per cápita que se reducen un $9 \%$, los demás aumentan en un porcentaje importante.

La evolución de los dos indicadores obtenidos, a lo largo del período considerado, también se puede observar en las Figuras 1 y 2 , y en ellas se aprecia 
mejor la tendencia descendente en todas las variables relacionadas con los ingresos propios (tributarios- ICA y predial y no tributarios) $\mathrm{y}$, en consecuencia, en una primera instancia, se podría concluir, que por lo menos en términos de los ingresos fiscales per cápita propios, hay convergencia, es decir que las desigualdades fiscales tienden a reducirse.

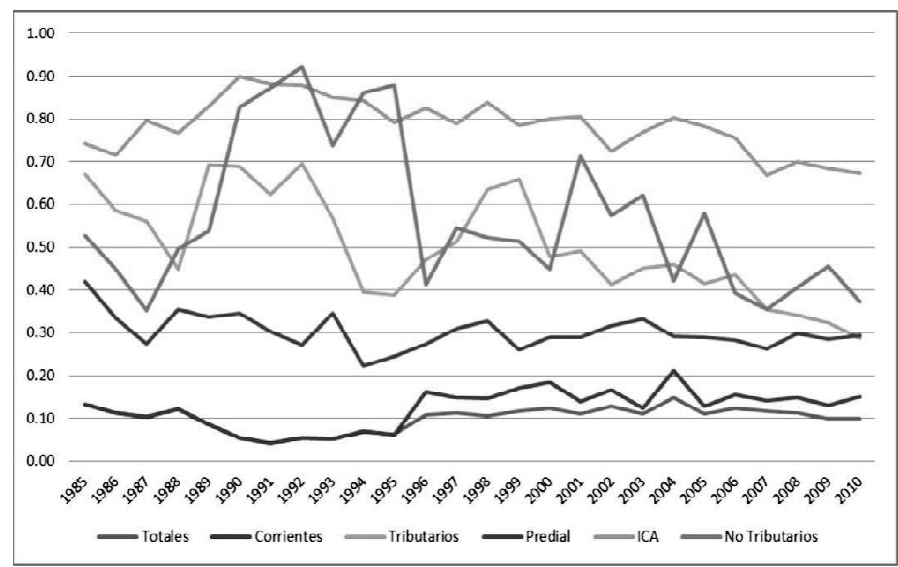

Figura 1. Municipios de Boyacá. Índice de Theil ingresos fiscales.

Fuente: cálculos del autor con base en las ejecuciones presupuestales del DNP, varios años.

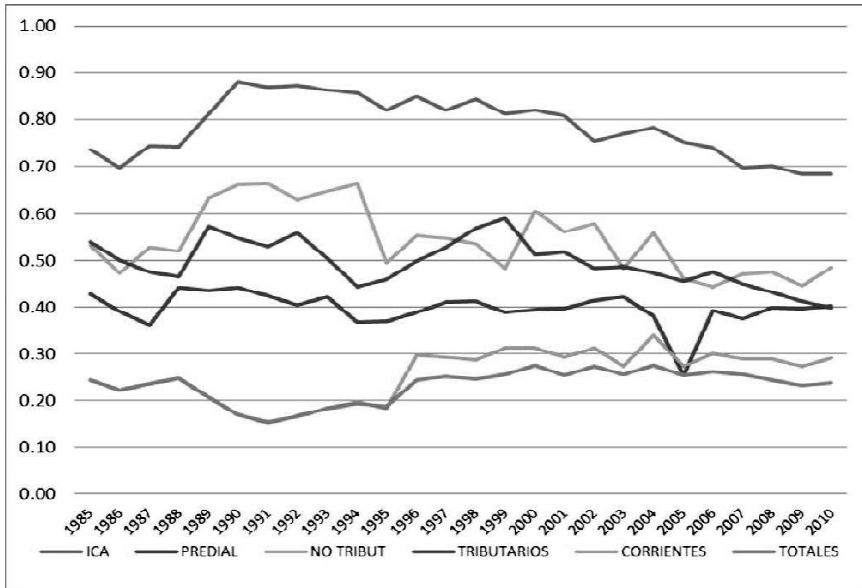

Figura 2. Municipios de Boyacá. GINI de ingresos fiscales. Fuente: cálculos del autor con base en las ejecuciones presupuestales del DNP, varios años. 
En cuanto al predial per cápita se refiere, se presenta una irregularidad en términos de niveles de desigualdad medida a través de los dos indicadores. Mientras el índice de Theil se ubicó alrededor del 0.30, el coeficiente de Gini fluctuó entre el 0.37 y el 0.44 .

Si se mantiene la hipótesis planteada inicialmente respecto a la posibilidad técnica de tomar el ICA y el predial como variables proxy de los ingresos municipales, y se acepta que estos ingresos per cápita se pueden utilizar como una aproximación para calcular las desigualdades entre los municipios de Boyacá, entonces, de acuerdo con el comportamiento de los indicadores mencionados, se puede decir que el ejercicio es útil para concluir que los grados de inequidad entre los municipios boyacenses se han reducido. Sin embargo, estos resultados deberán tomarse con cierta precaución, pues la reducción no implica mejoría en las condiciones económicas de los municipios de menor desarrollo, y más bien la reducción de la inequidad es consecuencia del esfuerzo fiscal realizado por todas las administraciones municipales ${ }^{14}$.

En general, la tasa de crecimiento promedio de los ingresos tributarios per cápita de los municipios del departamento fue de 28,2 para el periodo, para una media anual de $1,13 \%$ y solo treinta municipios tuvieron tasas de crecimiento por encima de la media entre los que se destacan Pisba, Paya, Tenza y Tópaga con tasas de $276.4 \%, 165.1 \%, 99.5 \mathrm{y}$ $96.7 \%$ respectivamente.

\section{Comportamiento de la desigualdad de los ingresos fiscales medida con la desviación estándar de los logaritmos (DEL) o convergencia sigma $(\sigma)$}

La convergencia sigma $(\sigma)$ medida a través de la desviación estándar de los logaritmos (DEL) de las variables analizadas, es una medida de dispersión que indica el grado de desigualdad existente entre distintos individuos, en nuestro caso entre los municipios del departamento de Boyacá. Si la dispersión de la variable analizada entre los miembros de una población, tiende a reducirse en el tiempo, entonces se presenta la convergencia sigma. En el supuesto de igualdad plena en la distribución de la variable per cápita analizada entre los municipios o provincias considerados, la desviación estándar sería cero. Por el contrario, a mayor desigualdad, le corresponde una mayor desviación estándar, expresada en puntos porcentuales.

Tanto en la Tabla 3 como en las Figuras 3 y $3^{\mathrm{a}}$, se presentan los resultados obtenidos para la desviación estándar del logaritmo, de los ingresos fiscales per cápita que se han venido considerando.

$14 \quad$ Las tasas de crecimiento de todos los ingresos propios (Predial, ICA, sobretasa a la gasolina y otros), lo mismo que la de los ingresos no tributarios son significativas, desmintiendo a quienes consideran que las transferencias incidieron en el aumento de la pereza fiscal (Núñez, 2005, p. 8). 
Finanzas públicas y desigualdad fiscal en los municipios de Boyacá, 1985-2010

Plinio A tanael Guerrero Guerrero

Tabla 3. Municipios de Boyacá. Desviación estándar de los logaritmos (DEL) o convergencia sigma $(\sigma)$.

\begin{tabular}{|l|c|c|c|c|c|c|}
\hline & Totales & Corrientes & Tributarios & Predial & ICA & $\begin{array}{c}\text { No } \\
\text { Tributarios }\end{array}$ \\
\hline 1985 & 0,49 & 0,49 & 1,00 & 0,79 & 1,77 & 1,34 \\
1986 & 0,39 & 0,39 & 0,89 & 0,71 & 1,50 & 1,02 \\
1987 & 0,44 & 0,44 & 0,84 & 0,65 & 1,60 & 1,10 \\
1988 & 0,43 & 0,43 & 0,87 & 0,89 & 1,76 & 1,09 \\
1989 & 0,38 & 0,38 & 1,19 & 0,93 & 2,19 & 1,67 \\
1990 & 0,31 & 0,31 & 1,11 & 0,99 & 3,18 & 1,97 \\
1991 & 0,29 & 0,29 & 1,11 & 1,02 & 3,37 & 1,93 \\
1992 & 0,33 & 0,33 & 1,13 & 0,88 & 3,36 & 1,99 \\
1993 & 0,34 & 0,33 & 0,98 & 0,87 & 3,23 & 1,94 \\
1994 & 0,35 & 0,35 & 0,86 & 0,81 & 3,22 & 1,93 \\
1995 & 0,34 & 0,34 & 0,91 & 0,80 & 2,87 & 1,43 \\
1996 & 0,59 & 0,68 & 1,01 & 0,83 & 3,35 & 1,51 \\
1997 & 0,50 & 0,63 & 1,14 & 0,88 & 3,30 & 1,68 \\
1998 & 0,48 & 0,55 & 1,20 & 0,88 & 2,95 & 1,90 \\
1999 & 0,59 & 0,63 & 1,31 & 0,85 & 2,88 & 1,56 \\
2000 & 0,51 & 0,57 & 1,07 & 0,83 & 2,72 & 1,82 \\
2001 & 0,45 & 0,53 & 1,14 & 0,84 & 2,37 & 1,53 \\
2002 & 0,50 & 0,59 & 1,06 & 0,87 & 2,12 & 1,90 \\
2003 & 0,45 & 0,50 & 1,03 & 0,95 & 2,13 & 1,23 \\
2004 & 0,49 & 0,68 & 0,89 & 0,78 & 2,12 & 1,30 \\
2005 & 0,45 & 0,49 & 0,85 & 0,78 & 1,75 & 0,95 \\
2006 & 0,46 & 0,54 & 0,89 & 0,79 & 1,82 & 0,96 \\
2007 & 0,45 & 0,52 & 0,88 & 0,79 & 1,63 & 1,02 \\
2008 & 0,44 & 0,51 & 0,83 & 0,85 & 1,54 & 1,05 \\
2009 & 0,41 & 0,44 & 0,80 & 0,82 & 1,43 & 0,97 \\
2010 & 0,42 & 0,49 & 0,77 & 0,93 & 1,54 & 1,04 \\
\hline
\end{tabular}

Fuente: cálculos del autor con base en las ejecuciones presupuestales del DNP, varios años.

En ellos se puede evidenciar que la trayectoria que describen las cifras que miden la inequidad en todos los ingresos per cápita estimados, señala la misma tendencia de la calculada con los índices de Theil y Gini. Igualmente se muestran tres períodos diferentes: en los primeros años es descendente, en una segunda etapa la inequidad se profundiza y a partir de 1995 la tendencia es descendente. El índice que muestra las mayores disparidades es el del ICA, que en algunos casos supera el $300 \%$.

Las desigualdades intermunicipales, tanto en el ICA, como en los impuestos no tributarios per cápita, tienden a disminuir desde 1991 cuando alcanza el máximo del 3.37 al 1.54 en el primero y del 1.99 al 0.94 en el segundo aunque con irregularidades. Algo similar 
acontece con los ingresos totales y los corrientes per cápita, que denotan una reducción de cerca del $20 \%$ en los dos primeros y del $54 \%$ en el segundo.

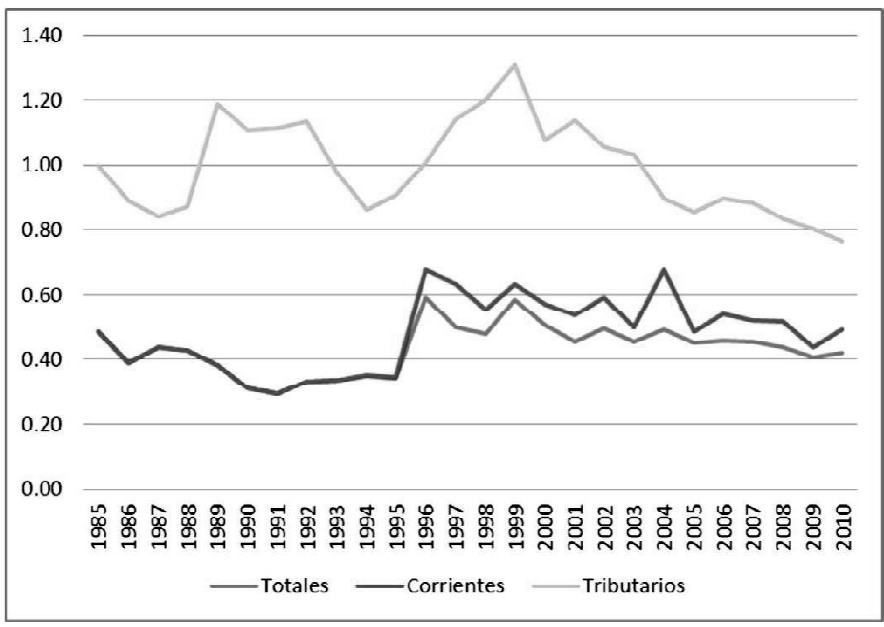

Figura 3. Municipios de Boyacá. Convergencia Sigma para ingresos fiscales. Fuente: cálculos del autor con base en las ejecuciones presupuestales del DNP, varios años.

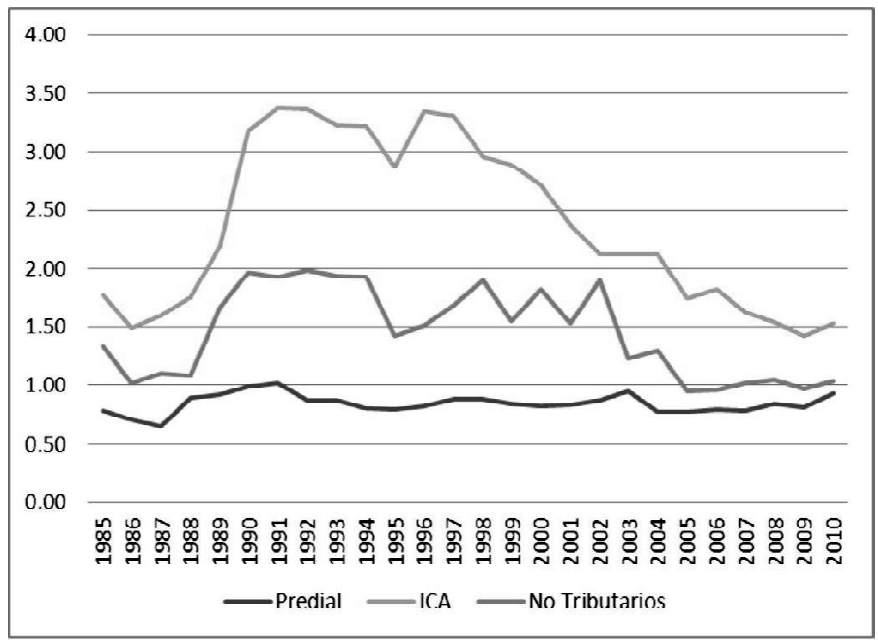

Figura 3a. Municipios de Boyacá. Convergencia Sigma para ingresos fiscales.

Fuente: cálculos del autor con base en las ejecuciones presupuestales del DNP, varios años. 
La inequidad que se registró en el ingreso predial per cápita presenta dos comportamientos. Los primeros tres años se reduce, pero a partir de 1988 se revierte hasta alcanzar un máximo de 1.02 en 1991; de ahí en adelante y hasta el 2010 se mantiene en un promedio de 0.84 , con una pequeña reducción que la situó por debajo del $80 \%$ del 2004 al 2007.

Por lo mostrado en los tres indicadores, se puede concluir que la inequidad en el ingreso predial per cápita se mantiene en los mismos niveles durante todo el período con algunos altibajos.

Las diferencias en relación con los ingresos totales per cápita se modifican levemente entre 1989 y 1995, pero en el resto del período continúan con el nivel de desigualdad con el que iniciaron. Los ingresos corrientes per cápita presentan el mismo comportamiento de los ingresos totales con diferencias ínfimas en algunos años. En todo caso, el nivel de desigualdad medido por este indicador es más alto que los anteriores (Theil y GINI), sin embargo muestran la misma tendencia en cuanto al comportamiento de la desigualdad a lo largo del tiempo, es decir, que esta no se modifica.

Al verificar el comportamiento de la estructura de ingresos desde el 2000 hasta el 2010, se encuentra que los ingresos de un poco más de las tres cuartas partes de los municipios de Boyacá (94 de los 123), dependieron en promedio en más del $70 \%$ de las transferencias de la nación, la mitad dependía en más del $80 \%$ y 10 en más del $90 \%$.

Diez de las ciudades cabecera de provincia, tuvieron ingresos por transferencias inferiores al $60 \%$. De ellas, Puerto Boyacá, con el $36.17 \%$ en promedio, es la que menos depende de las transferencias, le siguen en su orden Tunja (46.3\%), Chiquinquirá (46.6\%), Villa de Leyva (52.21\%), Miraflores (55.83\%), Guateque (56.5\%), Garagoa (56.73\%), Sogamoso (57.04\%), Duitama (59.88 \%) y Moniquirá (63.43 $\%)$. A las anteriores debe agregarse Nobsa (24.41\%), Paipa (35.3\%), Tibasosa $(42.98 \%)$ y Tuta $(52.48 \%)$, ubicadas en el llamado corredor industrial de Boyacá.

Como se sabe, los ingresos corrientes se obtienen de sumar los ingresos tributarios, los no tributarios y las transferencias, en tanto que los ingresos totales corresponden a la adición de los ingresos corrientes con los de capital. Las anteriores cifras indican por qué la transferencia de recursos del nivel central, juega un papel importante en la reducción de los niveles de inequidad medida a través de los tres indicadores, hecho que se constata en el menor nivel de inequidad tanto de los ingresos totales como de los corrientes per cápita, en relación con los niveles correspondientes a los ingresos propios. 


\section{Desigualdad intra provincial e interprovincial}

Esta parte del análisis se divide en tres acápites: en el primero se muestran las diferencias en cuanto a ingresos fiscales per cápita teniendo en cuenta los promedios del período. A continuación se indican las diferencias de algunos indicadores de bienestar como el NBI, el porcentaje de población considerado pobre y el Gini de gastos ${ }^{15} \mathrm{y}$, en último término, se presentan los resultados calculados para el Theil inter e intra provincias.

\section{Diferencias en los ingresos tributarios per cápita municipales}

La clasificación de los municipios de Boyacá teniendo en cuenta el promedio de los ingresos fiscales per cápita para el período 1985-2010, se relaciona en el Anexo 1. En él también se registran las diferencias de ingresos entre los municipios, expresadas en el número de veces que representa cada ingreso en relación con el que aparece clasificado en primer lugar. Allí se aprecia que los ingresos totales de Santa Rosa de Viterbo, Chiquinquirá, y Ráquira, que aparecen en el último lugar, son 5,9 veces el ingreso per cápita de los primeros: Busbanzá y Pisba. Igualmente, que los municipios que se ubican en los primeros lugares, corresponden a aquellos en los que se registran los mayores índices de INB, pobreza y Gini de gastos, con lo cual se deduce que las transferencias del nivel central les permite aparecer en los primeros lugares en el ingreso total per cápita.

No ocurre lo mismo con el ingreso tributario per cápita promedio, pues la diferencia entre el primero (Nobsa) y el último (Úmbita) es de 41,9 veces, producto de las inmensas disparidades en el ingreso per cápita del ICA, rubro en el que Nobsa, que es el primero, representó 538 veces el ingreso medio de Úmbita, que es el último. En este ingreso se presenta la mayor asimetría, a tal punto que el ingreso medio per cápita durante el período considerado de municipios como Tunja, fue 6,7 veces inferior al de Nobsa, Duitama 9.5 veces y Sogamoso casi 10 veces.

Las disparidades en el ingreso predial per cápita y en los no tributarios también son importantes. El predial per cápita de San Miguel de Sema representa 61 veces el de Quípama, que es el último, mientras que el no tributario de Paipa fue 20,6 veces el de San Pablo de Borbur.

\section{Inequidad intermunicipal medida por el NBI, el porcentaje de población pobre y el Gini de gastos}

La evolución de la equidad entre los habitantes de los municipios del

\footnotetext{
15 Los porcentajes de INB y de pobreza fueron tomados del DNP, mientras que el Gini de gastos fue tomado del
} Anexo 5: Indicadores por municipio en Fernández M, Hernández C, Ibáñez M y Jaramillo, C. (2009). 
departamento, también se puede examinar a través del análisis de algunos indicadores de bienestar, medidos en 1993 y en el 2005, los cuales se registran en el Anexo 2. Allí se advierte que en 32 municipios aumentó el INB, en 6 municipios se incrementó la pobreza, 3 de los cuales hacen parte de la provincia de Occidente y solamente en dos municipios se incrementó el GINI de gastos. El municipio de Güicán fue el único en el que los tres indicadores empeoraron de 1993 a 2005. En términos generales, estos indicadores evidencian una mejoría relativa en el bienestar de los habitantes de los municipios de Boyacá, al igual que en la equidad en términos de gasto.

Las cifras del NBI para 2005, presentan diferencias considerables entre los municipios, pues mientras Paipa registró $18.07 \%$, Chiquinquirá (17.87\%), Santa Rosa de Viterbo (17.14\%), Tibasosa (16.18\%), Nobsa (13.54\%), Tunja (12.01 $\%)$, Sogamoso (11.60\%) y Duitama
$(8.99 \%)$, del otro lado se encuentran municipios como Paya con $82.42 \%$, Chita (81.22\%), Pisba (80.77\%), Covarachía (79.65\%), Jericó (74\%), Socotá (72.35 \%) y Labranza Grande con el $70.15 \%$.

Los promedios simples generalmente ocultan situaciones en las que los indicadores pueden calificarse como graves. Es el caso del indicador que muestra el porcentaje de población pobre en los municipios boyacenses. En promedio, este porcentaje bajó del 63.81 $\%$ en 1993 al $49.23 \%$ en el 2005 , es decir 14.58 puntos, acercándose a los promedios nacionales de $43 \%$ y del $41 \%$ en los mismos años. En el Tabla 4 se muestra el porcentaje de población considerado como pobre entre los primeros diez y los últimos diez municipios boyacenses y la posición que ocupan al ordenarlos de mayor a menor. En 1993, la diferencia entre el de menor proporción de población pobre y el de mayor porcentaje era de 45 puntos, con una leve reducción de 3 puntos porcentuales en el 2005. 
Tabla 4. Municipios de Boyacá. Porcentaje de población en condiciones de pobreza.

\begin{tabular}{|c|c|c|c|c|c|}
\hline \multicolumn{3}{|c|}{1993} & \multicolumn{3}{|c|}{2005} \\
\hline Lugar & Municipio & \% Pobreza & Lugar & Municipio & \% Pobreza \\
\hline 1 & Chíquiza & 82,0 & 1 & Pisba & 69,0 \\
\hline 2 & Chivatá & 80,0 & 2 & Güicán & 64,0 \\
\hline 3 & Soracá & 79,0 & 3 & Corrales & 64,0 \\
\hline 4 & Boavita & 79,0 & 4 & Paya & 63,0 \\
\hline 5 & Paya & 77,0 & 5 & Pauna & 63,0 \\
\hline 6 & San José de Pare & 77,0 & 6 & Labranzagrande & 63,0 \\
\hline 7 & Chita & 76,0 & 7 & Otanche & 63,0 \\
\hline 8 & Beteitiva & 76,0 & 8 & Chita & 61,0 \\
\hline 9 & Motavita & 76,0 & 9 & Quípama & 60,0 \\
\hline 10 & Socotá & 76,0 & 10 & Maripí & 59,0 \\
\hline 114 & Puerto Boyacá & 50,0 & 114 & Belén & 40,0 \\
\hline 115 & Villa de Leyva & 50,0 & 115 & Tibasosa & 37,0 \\
\hline 116 & Santa María & 49,0 & 116 & Villa de Leyva & 37,0 \\
\hline 117 & Santa Rosa de Viterbo & 48,0 & 117 & Santa Rosa de Viterbo & 36,0 \\
\hline 118 & Chiquinquirá & 47,0 & 118 & Paipa & 36,0 \\
\hline 119 & Duitama & 41,0 & 119 & Chiquinquirá & 34,0 \\
\hline 120 & Berbeo & 40,0 & 120 & Sogamoso & 32,0 \\
\hline 121 & Sogamoso & 39,0 & 121 & Duitama & 28,0 \\
\hline 122 & Tunja & 39,0 & 122 & Nobsa & 27,0 \\
\hline 123 & Nobsa & 37,0 & 123 & Tunja & 27,0 \\
\hline \multicolumn{2}{|c|}{ Promedio Municipios de Boyacá } & 63,8 & & & 49,2 \\
\hline \multicolumn{2}{|c|}{ Promedio Nacional } & 43,0 & & & 41,0 \\
\hline
\end{tabular}

Fuente: cálculos del autor con base en las ejecuciones presupuestales del DNP, varios años.

En la parte superior de la Tabla 4 se observa claramente que los mayores índices de pobreza se registran en municipios que tradicionalmente se han reconocido como de menor desarrollo relativo, en tanto que en la parte inferior se relacionan los de mayor desarrollo. Paya, Chita, Gachantivá y BoyacáBoyacá, son los únicos municipios en los que la situación no cambió entre 1993 y el 2005.
En 1993, en solo cinco de los 123 municipios del departamento, el porcentaje de pobreza estaba por debajo de la media nacional (Duitama: $41 \%$, Berbeo con 40 $\%$, Sogamoso y Tunja con $39 \%$ y Nobsa con $37 \%$ ), para el 2005 aumentó a once, y en ellos se concentraba el $42,2 \%$ de la población del departamento (529.548), es decir que de las 527.742 personas que estaban catalogadas como pobres $(42,02$ $\%$ de la población total del departamento), 
365.862 corresponde a los municipios que están por debajo de la media nacional.

El bienestar de los habitantes boyacenses a nivel de provincia medido a través de los mismos indicadores se sintetiza en el Tabla 5. En cuanto al NBI las provincias de centro, Sugamuxi, Tundama y Puerto Boyacá, en las que se reconoce un mayor nivel de crecimiento económico, las tasas de población con necesidades básicas insatisfechas son relativamente bajas, mientras que en Cubará y la Libertad supera el $75 \%$ de la población.

Tabla 5. Provincias de Boyacá. Promedios de algunos indicadores de bienestar.

\begin{tabular}{|l|c|c|c|c|c|c|}
\hline \multirow{2}{*}{ Provincia } & \multicolumn{2}{|c|}{ \% Personas en NBI } & \multicolumn{2}{c|}{ \% pobreza } & \multicolumn{2}{c|}{ Gini de gastos } \\
\cline { 2 - 6 } & $\mathbf{1 9 9 3}$ & $\mathbf{2 0 0 5}$ & $\mathbf{1 9 9 3}$ & $\mathbf{2 0 0 5}$ & $\mathbf{1 9 9 3}$ & $\mathbf{2 0 0 5}$ \\
\hline Centro & 42,78 & 40,71 & 70,33 & 48,07 & 0,47 & 0,40 \\
Gutiérrez & 53,99 & 59,03 & 66,17 & 51,00 & 0,46 & 0,44 \\
La Libertad & 76,97 & 68,74 & 65,00 & 62,50 & 0,46 & 0,43 \\
Lengupá & 51,40 & 35,41 & 56,17 & 50,33 & 0,47 & 0,42 \\
Márquez & 47,27 & 39,77 & 70,00 & 50,10 & 0,46 & 0,41 \\
Neira & 41,92 & 32,89 & 55,67 & 47,83 & 0,46 & 0,42 \\
Norte & 56,74 & 55,55 & 65,11 & 48,89 & 0,46 & 0,43 \\
Occidente & 54,94 & 42,55 & 61,80 & 54,00 & 0,49 & 0,42 \\
Oriente & 37,23 & 36,71 & 61,88 & 47,25 & 0,45 & 0,42 \\
Ricaurte & 49,88 & 42,65 & 63,92 & 49,54 & 0,48 & 0,43 \\
Sugamuxi & 36,04 & 34,06 & 61,62 & 44,46 & 0,45 & 0,41 \\
Tundama & 38,13 & 31,11 & 58,89 & 42,89 & 0,46 & 0,41 \\
Valderrama & 54,21 & 55,40 & 69,71 & 50,71 & 0,46 & 0,41 \\
Zona manejo especiales & 39,28 & 39,31 & 50,00 & 45,00 & 0,45 & 0,42 \\
Distrito Fronterizo & 78,41 & 58,46 & 58,00 & 52,00 & 0,47 & 0,48 \\
\hline Promedio & $\mathbf{5 2 , 6 6}$ & $\mathbf{4 6 , 8 9}$ & $\mathbf{6 9 , 8 6}$ & $\mathbf{5 4 , 0 4}$ & $\mathbf{0 , 5 1}$ & $\mathbf{0 , 4 6}$ \\
\hline
\end{tabular}

Fuente: cálculos del autor con base en las ejecuciones presupuestales del DNP, varios años.

Para el año 2005, las provincias de Gutiérrez y Valderrama en vez de mejorar empeoraron, ya que el número de personas con NBI aumentó un 5,4 \% y el $1,19 \%$ respectivamente.

El porcentaje de población en línea de pobreza entre los dos censos, se redujo en todas las provincias del departamento, en un rango amplio que va del $5 \%$ en Puerto Boyacá, al $22.27 \%$ en la del Centro, para un promedio del $12.65 \%$, que resulta importante en términos de equidad. Por subregiones se evidencian diferencias hasta de 20 puntos entre el valor mínimo ( $43 \%$ en la del Tundama) y el máximo (el $62.5 \%$ en La Libertad), la más alejada de los centros de mercadeo y con fuertes problemas de vías de comunicación.

El Gini de gastos a nivel de provincias se redujo, aunque levemente, con excepción de Cubará. 


\section{Theil intra e interprovincias de Boyacá}

Para medir el grado de desigualdad entre las provincias del departamento, se empleó el índice de Theil, el cual permite calcular, además de la inequidad entre los municipios, la inaquidad entre las diferentes provincias.

Tabla 6. Municipios de Boyacá. Índices de Theil de los ingresos fiscales.

\begin{tabular}{|c|c|c|c|c|c|c|c|c|c|}
\hline \multirow{2}{*}{$\begin{array}{c}\text { Intra } \\
\text { provincia }\end{array}$} & \multicolumn{2}{|c|}{ Ingresos totales } & \multicolumn{2}{c|}{ Tributarios } & \multicolumn{2}{c|}{ Predial } & \multicolumn{2}{c|}{ ICA } \\
\cline { 2 - 9 } & $\begin{array}{c}\text { Inter } \\
\text { provincia }\end{array}$ & $\begin{array}{c}\text { Intra } \\
\text { provincia }\end{array}$ & $\begin{array}{c}\text { Inter } \\
\text { provincia }\end{array}$ & $\begin{array}{c}\text { Intra } \\
\text { provincia }\end{array}$ & $\begin{array}{c}\text { Inter } \\
\text { provincia }\end{array}$ & $\begin{array}{c}\text { Intra } \\
\text { provincia }\end{array}$ & $\begin{array}{c}\text { Inter } \\
\text { provincia }\end{array}$ & $\begin{array}{c}\text { Intra } \\
\text { provincia }\end{array}$ \\
\hline 1985 & 0,11 & 0,02 & 0,47 & 0,20 & 0,30 & 0,12 & 0,63 & 0,31 \\
1986 & 0,10 & 0,02 & 0,42 & 0,17 & 0,24 & 0,09 & 0,60 & 0,29 \\
1987 & 0,09 & 0,02 & 0,42 & 0,14 & 0,19 & 0,08 & 0,66 & 0,41 \\
1988 & 0,10 & 0,02 & 0,33 & 0,11 & 0,25 & 0,10 & 0,66 & 0,31 \\
1989 & 0,08 & 0,01 & 0,51 & 0,18 & 0,21 & 0,13 & 0,74 & 0,35 \\
1990 & 0,05 & 0,01 & 0,49 & 0,20 & 0,21 & 0,14 & 0,80 & 0,49 \\
1991 & 0,03 & 0,01 & 0,45 & 0,17 & 0,21 & 0,09 & 0,78 & 0,47 \\
1992 & 0,05 & 0,01 & 0,52 & 0,18 & 0,19 & 0,09 & 0,75 & 0,51 \\
1993 & 0,04 & 0,01 & 0,41 & 0,16 & 0,25 & 0,09 & 0,72 & 0,46 \\
1994 & 0,06 & 0,01 & 0,28 & 0,12 & 0,16 & 0,06 & 0,71 & 0,46 \\
1995 & 0,06 & 0,00 & 0,28 & 0,11 & 0,18 & 0,07 & 0,64 & 0,42 \\
1996 & 0,08 & 0,02 & 0,32 & 0,15 & 0,21 & 0,06 & 0,68 & 0,46 \\
1997 & 0,08 & 0,03 & 0,33 & 0,18 & 0,23 & 0,07 & 0,60 & 0,47 \\
1998 & 0,09 & 0,02 & 0,36 & 0,28 & 0,25 & 0,07 & 0,65 & 0,54 \\
1999 & 0,10 & 0,02 & 0,39 & 0,27 & 0,22 & 0,05 & 0,62 & 0,43 \\
2000 & 0,10 & 0,03 & 0,36 & 0,11 & 0,23 & 0,06 & 0,65 & 0,44 \\
2001 & 0,09 & 0,02 & 0,36 & 0,13 & 0,23 & 0,06 & 0,63 & 0,47 \\
2002 & 0,10 & 0,03 & 0,31 & 0,10 & 0,26 & 0,06 & 0,57 & 0,36 \\
2003 & 0,09 & 0,02 & 0,35 & 0,10 & 0,27 & 0,07 & 0,64 & 0,36 \\
2004 & 0,11 & 0,04 & 0,37 & 0,09 & 0,24 & 0,05 & 0,69 & 0,36 \\
2005 & 0,09 & 0,03 & 0,33 & 0,09 & 0,24 & 0,05 & 0,66 & 0,35 \\
2006 & 0,09 & 0,03 & 0,33 & 0,11 & 0,23 & 0,06 & 0,63 & 0,34 \\
2007 & 0,09 & 0,03 & 0,25 & 0,10 & 0,21 & 0,05 & 0,54 & 0,28 \\
2008 & 0,08 & 0,03 & 0,26 & 0,09 & 0,24 & 0,06 & 0,57 & 0,30 \\
2009 & 0,07 & 0,03 & 0,24 & 0,09 & 0,23 & 0,06 & 0,53 & 0,32 \\
2010 & 0,06 & 0,04 & 0,21 & 0,07 & 0,23 & 0,06 & 0,51 & 0,34 \\
\hline
\end{tabular}

Fuente: cálculos del autor con base en las ejecuciones presupuestales del DNP, varios años.

Los resultados obtenidos al calcular el coeficiente de Theil (Tabla 6), permiten ver que la aportación intraprovincia a la desigualdad en Boyacá en el período de 1985 a 2010, para los ingresos totales per cápita, se puede dividir en tres sub períodos: el primero va de 1985 a 1991, en el que la tendencia es hacia la reducción de las asimetrías entre los municipios que integran las provincias, 
bajando del 0.11 al 0.03. A partir de 1992 la tendencia se revierte hasta el 2004 cuando alcanza el mismo nivel de 1985. En adelante vuelve a disminuir hasta llegar al 0.06. En cambio las diferencias interprovincia oscilan entre el $1 \%$ yel $4 \%$, lo que indica que la disparidad se presenta entre municipios, no entre provincias.
Las diferencias se presentan en el interior de las provincias de Centro, Sugamuxi, Occidente, Ricaurte y Tundama, en las que se localizan los municipios que concentran el mayor número de población y la presencia de economías de aglomeración, que les permite percibir ingresos propios más altos.

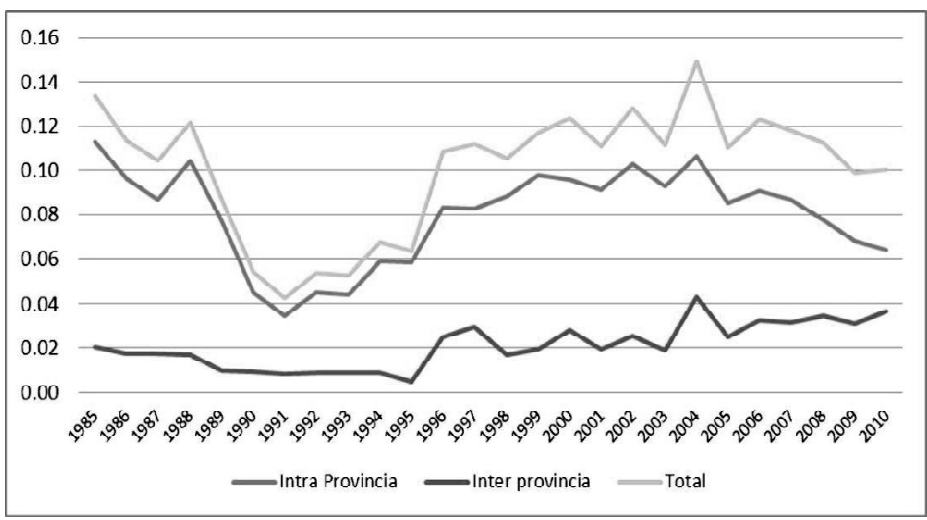

Figura 4. Índice deTheil. Ingresos totales per cápita municipios de Boyacá.

Fuente: cálculos del autor con base en las ejecuciones presupuestales del DNP, varios años.

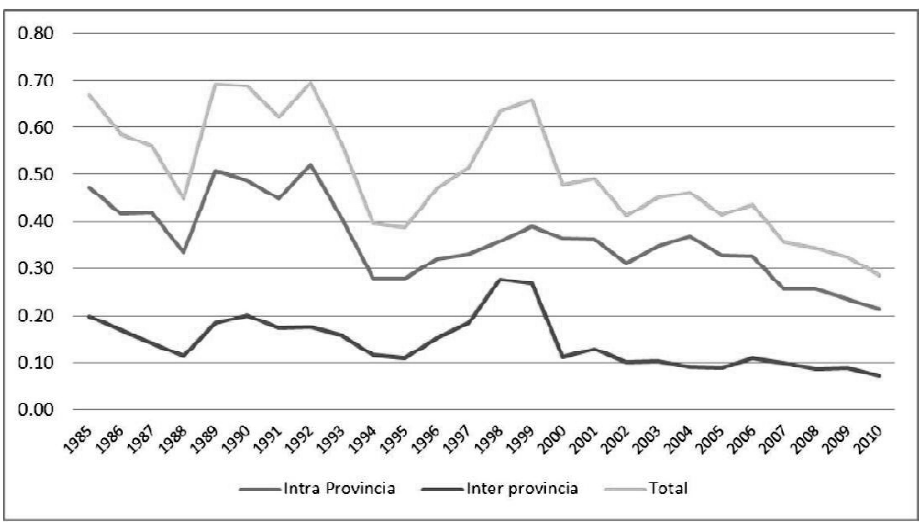

Figura 5. Municipios de Boyacá. Índice de Theil de los ingresos tributarios per cápita.

Fuente: cálculos del autor con base en las ejecuciones presupuestales del DNP, varios años. 
El nivel de la desigualdad en el interior de cada provincia se puede constatar en el Anexo 3, en el que se aprecia una reducción de la proporción de la desigualdad de las citadas provincias, y un aumento de la inequidad dentro de provincias como La Libertad, Oriente y Valderrama.

En el campo de ingresos tributarios per cápita, alrededor del $72 \%$ de la desigualdad entre los municipios de Boyacá se explica por la inequidad en el interior de las provincias y de estas, de nuevo, las de Centro, Sugamuxi, Occidente, Ricaurte y Tundama explican, en promedio, más del $80 \%$ de la desigualdad dentro de ellas (Anexo 4); mientras que el componente interprovincial fue del $28 \%$, con un índice que fluctúa entre 0.20 y el 0.10 , en todo caso como se aprecia en la Figura 5 y en la Tabla 7, la tendencia para los dos componentes de desigualdad es convergente.
En la Figura 6 se muestra el comportamiento del índice de Theil del predial per cápita y la participación de la desigualdad intra e interprovincias. La línea azul revela la mayor contribución de la desigualdad dentro de las provincias a la desigualdad total y describe la evolución de la desigualdad en el interior de las provincias a lo largo del período. En la primera parte, la tendencia es descendente aunque irregular hasta 1994, de 1995 a 2003 la inequidad en el interior de las provincias se amplía hasta alcanzar el 0.27 , y en el último período se reduce un $3 \%$. La desigualdad interprovincial representada por la línea roja se mantiene entre el 5 y el $7 \%$.

Las diferencias en términos de inequidad para este impuesto son notorias, ya que solo 6 de las 15 provincias responden por el 81,4 $\%$ de la desigualdad intraprovincias: Occidente con el 34,1\%, Sugamuxi con el $17.7 \%$, Ricaurte con el $11.3 \%$, Centro con el $10.8 \%$, Tundama con el $7.5 \%$ y Oriente con el $3.2 \%$ (Anexo 5).

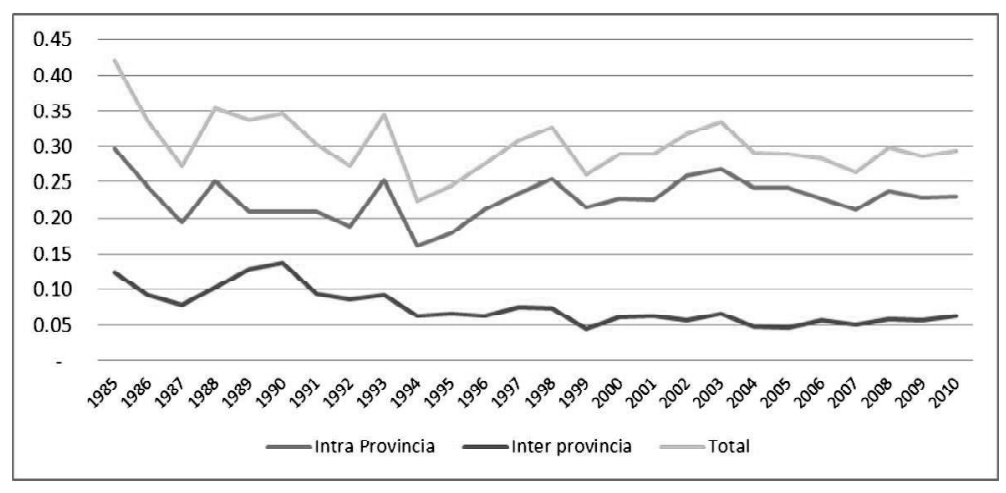

Figura 6. Municipios de Boyacá. Índice de Theil del ingreso predial per cápita.

Fuente: cálculos del autor con base en las ejecuciones presupuestales del DNP, varios años. 
Finanzas públicas y desigualdad fiscal en los municipios de Boyacá, 1985-2010

Plinio Atanael Guerrero Guerrero

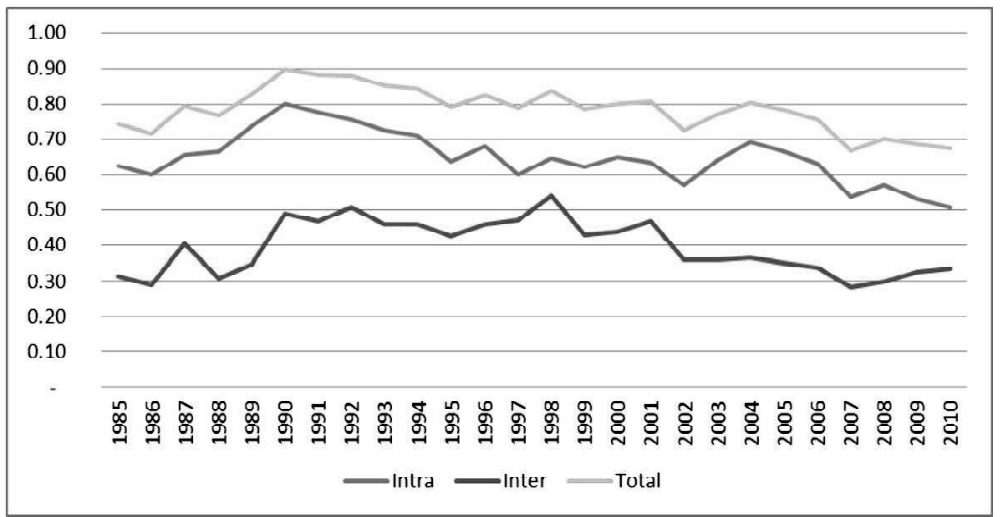

Figura 7. Municipios de Boyacá. Índice de Theil de industria y comercio.

Fuente: cálculos del autor con base en las ejecuciones presupuestales del DNP, varios años.

Al calcular la participación de las desigualdades interregionales en las desigualdades totales, para los ingresos de industria y comercio per cápita se tiene que, en promedio, el $83 \%$ de la desigualdad total entre los municipios de Boyacá, corresponde a la desigualdad que se presenta en el interior de las provincias. De nuevo, las asimetrías que tienen lugar en el interior de las provincias de Sugamuxi, Centro y Tundama explican un porcentaje considerable de la desigualdad intraprovincial, fundamentalmente por la diferencia en los ingresos del ICA que perciben los municipios de Nobsa y Tibasosa en la provincia de Sugamuxi y Tuta en la provincia del Centro.

Al excluir los municipios de Nobsa y Tuta en el análisis del comportamiento de la desigualdad del ICA per cápita intraprovincia, se observa que esta disminuye ostensiblemente, en relación con la asimetría en presencia de los municipios mencionados. No obstante, esto no ocurre a lo largo del período de análisis sino que se denotan tres subperíodos: el primero va desde 1985 hasta 1995 , la inequidad es en promedio un $22 \%$ menor. De 1996 al 2002, las diferencias se reducen significativamente por el pago del ICA que realiza la empresa AES Chivor CIA \& CSA ESP a los municipios del área de influencia. Desde el 2003 nuevamente se amplían las diferencias, a pesar de que la tendencia es descendente para las dos líneas, con una discrepancia del $14 \%$ (Tabla 7 y Figura 8). En todo caso, la inequidad es en promedio del $17 \%$, con lo que se resalta la incidencia sobre el indicador total intraprovincia al incluir los municipios de Nobsa y Tuta.

La inequidad interprovincial se reduce del $40 \%$ al $20 \%$ en los primeros seis años, 
pero en adelante la tendencia es claramente creciente para ubicarse en el $49 \%$, lo cual coincide con el resultado obtenido a través de la convergencia sigma $(\sigma)$.

Por otra parte, en la construcción del índice de Theil y de acuerdo con Lora (2008, p. 50), dado que “...el término mide la desviación relativa del ingreso del individuo con respecto al promedio. $\mathrm{Su}$ logaritmo, por consiguiente, es negativo para los individuos con ingresos por debajo del promedio y positivo para los demás", se encontró que al iniciar el período, el $80 \%$ de los municipios (94) se situaba por debajo de la media de los ingresos tributarios per cápita, y solo 24 la rebasaban, no obstante la situación cambia al final ya que termina con 40 en el penúltimo año, y 38 en el 2010, hecho que indicaría la reducción de la dispersión en dichos ingresos.

Tabla 7. Theil del ICA intra provincia sin y con Nobsa y Tuta.

\begin{tabular}{|c|c|c|c|c|c|c|c|c|c|c|c|c|c|c|c|c|c|c|c|c|c|c|c|}
\hline & & & & & & & & & & & & & & & 0 & & & 0 & 0 & & & & \\
\hline & & & & & & & & & & & & & & & 0 & 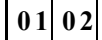 & & & & & & & \\
\hline & & & & & & & & & & & & & & & & \begin{tabular}{|c|l|}
0, & 0, \\
62 & 52 \\
\end{tabular} & & & & & & & \\
\hline & & & & & & & $\left|\begin{array}{c}0 \\
78\end{array}\right|$ & & & & & & & & & \begin{tabular}{|c|c|}
0, & 0, \\
63 & 57 \\
\end{tabular} & & & & & & & \\
\hline & & & & & & & 0, & & & & & & & & & & & \begin{tabular}{|l|}
0 \\
20
\end{tabular} & \begin{tabular}{|l|}
0, \\
\end{tabular} & & & & \\
\hline & & & \begin{tabular}{|c|}
0, \\
34
\end{tabular} & & & & 22 & & & & & & & & & & & & & & & & \\
\hline
\end{tabular}

Fuente: cálculos del autor con base en las ejecuciones presupuestales del DNP, varios años.

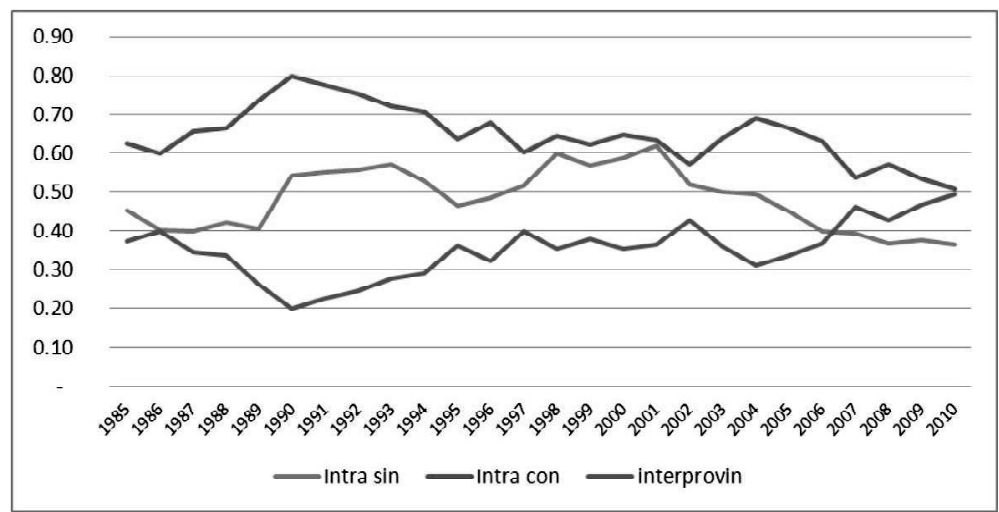

Figura 8. Municipios de Boyacá. Theil del ICA intraprovincia, e interprovincia, sin Nobsa y Tuta.

Fuente: cálculos del autor con base en las ejecuciones presupuestales del DNP, varios años. 


\section{CONCLUSIONES}

Los resultados obtenidos para medir la desigualdad entre los municipios de Boyacá a través de los tres indicadores aplicados para los ingresos totales y corrientes per cápita, demuestran que esta es la menor de todas. Los tres índices son iguales hasta 1995, pero a partir de allí se observa que el de los ingresos corrientes per cápita aumenta en relación con los totales como consecuencia de las desigualdades en los ingresos tributarios. El Theil de los ingresos totales per cápita fluctúa entre el 0.11 y el 0.10 , con un máximo de 0.15 en 2004, y el Gini varía entre el 0.17 y el 0.28 ; la desigualdad de los ingresos corrientes está por encima de los totales desde 1995 con una diferencia promedio de 0.06 , corriendo prácticamente en paralelo en el subperiodo 1995-2010. El nivel de desigualdad medido por la convergencia sigma (ó) es más alto que los anteriores (Theil y GINI), sin embargo muestran la misma tendencia en cuanto al comportamiento de la desigualdad a lo largo del tiempo.

La evolución de los tres indicadores obtenidos (Theil, GINI y convergencia sigma), a lo largo del período de tiempo considerado, para los ingresos propios (tributarios- ICA y predial y no tributarios), muestra una tendencia descendente desde la segunda parte de la década de los noventa $y$, en consecuencia, en una primera instancia, se podría concluir que por lo menos en términos de los ingresos fiscales per cápita propios, hay convergencia, es decir que las desigualdades fiscales tienden a reducirse.

Dado que las diferencias que se observan entre los índices que miden las desigualdades de los ingresos totales y corrientes per cápita y los que miden la inequidad de los ingresos propios, son considerables, se puede concluir que las transferencias que realiza el nivel central, sí han contribuido a reducir la desigualdad entre los municipios, por lo menos en términos fiscales.

Sin embargo, estos resultados deben tomarse con precaución, pues la reducción no necesariamente implica mejoría en las condiciones económicas de los municipios de menor desarrollo, y más bien es consecuencia del esfuerzo fiscal realizado por todas las administraciones municipales, si se tiene en cuenta que hay un crecimiento importante de todos los ingresos propios (predial, ICA, sobretasa a la gasolina y otros), lo mismo que la de los ingresos no tributarios.

En el ámbito de ingresos tributarios per cápita, alrededor del $72 \%$ de la desigualdad entre los municipios de Boyacá se explica por la inequidad en el interior de las provincias, siendo las de Centro, Sugamuxi, Occidente, Ricaurte y Tundama las que explican, en promedio, más del $80 \%$ de la desigualdad; mientras que el componente interprovincial fue del $28 \%$, con un índice que fluctúa entre 0.20 y el 0.10 , en todo caso la tendencia para 
los dos componentes de desigualdad es convergente.

Las diferencias en términos de inequidad para el predial per cápita son notorias, ya que solo 6 de las 15 provincias responden por el $81,4 \%$ de la desigualdad intraprovincias: Occidente con el 34,1\%, Sugamuxi con el $17.7 \%$, Ricaurte con el $11.3 \%$, Centro con el $10.8 \%$, Tundama con el $7.5 \%$ y Oriente con el $3.2 \%$.

En promedio, el $83 \%$ de la desigualdad total de los ingresos de industria y comercio per cápita, entre los municipios de Boyacá, corresponde a la desigualdad que se presenta en el interior de las provincias. Las asimetrías tienen lugar en el interior de las provincias de Sugamuxi, Centro y Tundama, fundamentalmente por la diferencia en los ingresos del ICA que perciben los municipios de Nobsa y
Tibasosa en la provincia de Sugamuxi y Tuta en la provincia del Centro.

Si se calcula la inequidad del ICA per cápita intraprovincia sin incluir los municipios de Nobsa y Tuta en el análisis, se observa que disminuye ostensiblemente, en relación con la asimetría en presencia de los municipios mencionados. La diferencia en términos de inequidad es en promedio del $17 \%$, con lo que se resalta la incidencia sobre el indicador total intraprovincia al incluir los referidos municipios.

Finalmente, algunos indicadores de bienestar como el NBI, el porcentaje de población considerado pobre y el Gini de gastos calculados por algunas entidades y autores para los años de 1993 y 2005 , presentan disminuciones importantes que corrobaran en cierta forma la mejora en los indicadores de equidad.

\section{Referencias}

Bacallao, J. (2007, oct-dic). Indicadores basados en la noción de entropía para la medición de las desigualdades sociales en salud. Revista cubana de salud pública, 33(4). Recuperado de: http://www.scielosp.org/scielo.php?script=sci_arttext\&pid=S086434662007000400007\&lng=es\&nrm=iso\&tlng=es

Betancurt et al. (2002). Observaciones a la Ley del Sistema General de Participaciones. Revista de la Contraloría General de la República, CGN, (289), 58-69.

Bonet, J. (2004). Descentralización fiscal y disparidades en el ingreso regional: la experiencia colombiana. Documentos de trabajo sobre economía regional. Cartagena: Banco de la República. Recuperado de: http://www.banrep.gov.co/es/publicaciones?keys

Bonet, J. \& Meisel, A. (2007). Polarización del ingreso per cápita departamental en Colombia, 1975 -2000. En E. Rodríguez \& L. Vallejo (comp.). Modelos de desarrollo y economía regional. (pp. 170-199). Tunja: CENES, UPTC. 
Bonilla, R. (2011, 5 de nov.). Impuestos son la clave para que exista equidad según experto. Recuperado de: http://www.portafolio.co/economial

CEGA (2006). Ingreso, consumo y ahorro en los departamentos de Colombia, 1975-2000, Vol. 2. En Sistema simplificado de cuentas departamentales. Bogotá: s.n.

Debraj, R. (2000). Economía del desarrollo (1 ed.). Barcelona: Antoni Bosch.

DEPARTAMENTO NACIONAL DE PLANEACION -DNP- (2008). Técnicas para el análisis de la gestión económica y financiera de las entidades territoriales. Grupo de Análisis y Seguimiento a Finanzas Territoriales-GAFT, Bogotá D.C.

Fernández M, Hernández C, Ibáñez M. \& Jaramillo, C. (2009). “Dinámicas departamentales de pobreza en Colombia 1993-2005”. Documento de Trabajo N³3. Programa Dinámicas Territoriales Rurales. Rimisp, Santiago, Chile.

González, J. (2006). “La pobreza disminuye pero las brechas aumentan”, recuperado de: http:/ /razonpublica.com/index.php/component/content/article/167-articulos-recientes-/2369-lapobreza-disminuye-pero-las-brechas-aumentan.html el 15 de Septiembre de 2012.

González, J. (2006). Ética económica y politicas sociales. Medellín: Corporación Región.

Lora, E. (2008). Técnicas de medición económica. Metodología y aplicaciones en Colombia. (4 ed.). Bogotá: Alfa Omega.

Márquez, J. (2011). Disparidad y divergencia económica en centro américa 1950-2008. San Salvador: Editorial Universidad Francisco Gaviria. Recuperado de: http://www.ufg.edu.sv/ icti/algo.php? $\mathrm{x}=\mathrm{EB}$

Martínez, A. (2006). "Determinantes del PIB per cápita de los departamentos colombianos 1975-2003” en ARCHIVOS DE ECONOMÍA, Banco de la República.

Marx, C. (1859). Contribución a la crítica de la economía política. M. Kuznetsov (Trad.). México: Editorial Progreso.

Medina, F. (2001). Consideraciones sobre el índice de Gini para medir la concentración del ingreso. Santiago de Chile: CEPAL. Recuperado de: http://www.eclac.org/publicaciones/ xml/0/6570/lcl1493e.pdf

Musgrave, R. \& Musgrave, B. (1992). Hacienda pública: teórica y aplicada; Barcelona. Traducción de Corona Ramón, Juan Francisco; Lozano Irueste, José María. Editorial McGraw Hill. 5a edición. 
Núñez, J. (2005). Diagnóstico básico de la situación de los ingresos por impuestos del orden municipal en Colombia. Documento CEDE 44. Bogotá: Universidad de los Andes.

Núñez, J. \& Sánchez, F. (2000). Geography and economic development in Colombia: a municipal approach. Working Paper No. 130, Bogotá: CEDE, Facultad de Economía Universidad de los Andes, BID. Recuperado de: http://papers.ssrn.com/sol3/ papers.cfm?abstract_id $=1814677$.

Peña, A. (2004). Las disparidades económicas intrarregionales en Andalucía. TESIS DOCTORAL, Servicio de Publicaciones de la Universidad de Cádiz, España. Recuperado de: www.uca.es/publicaciones publicaciones@uca.es el 03/03/2013.

Sala-i-Martin, X. (1999). Apuntes de crecimiento económico. (2 ed.). Barcelona: Antoni Bosch.

Sen, A. (1992). Nuevo examen de la desigualdad. A. Marín (Trad.). Madrid: Alianza.

Shah, A. (2005). Fiscal federalism and macroeconomic governance: for better or for worse. World Bank Working Paper. USA: WB.

Thurrow, L. (1973). Toward a definition of economic justice. The Public Interest, (31).

Tiana, A. (2010). Descentralización y equidad. Director General del Centro de Altos Estudios Universitarios. Recuperado de: http://www.tarea.org.pe/tarea.php?numero_edicion=75 
Anexo 1. Municipios de Boyacá. Relaciones entre diferentes ingresos fiscales per cápita.

\begin{tabular}{|c|c|c|c|c|c|c|c|c|c|}
\hline Entidad & Total & Entidad & $\begin{array}{l}\text { Tribu- } \\
\text { tarios }\end{array}$ & Entidad & ICA & Entidad & Predial & Entidad & $\begin{array}{l}\text { No Tri- } \\
\text { butarios }\end{array}$ \\
\hline Busbanzá & 1,0 & Nobsa & 1,0 & Nobsa & 1,0 & $\begin{array}{l}\text { San Miguel de } \\
\text { Sema }\end{array}$ & 1,0 & Paipa & 1,0 \\
\hline Pisba & 1,0 & Tuta & 1,7 & Tuta & 1,7 & Villa de Leyva & 1,7 & Campohermoso & 1,2 \\
\hline Chivor & 1,2 & Tibasosa & 2,4 & Tibasosa & 3,3 & Nobsa & 1,9 & \begin{tabular}{|l|l} 
Páez \\
\end{tabular} & 1,3 \\
\hline La Victoria & 1,4 & Tunja & 2,7 & Puerto Boyacá & 4,5 & Tunja & 2,0 & Santa Sofía & 1,4 \\
\hline Paya & 1,5 & Puerto Boyacá & 2,9 & Miraflores & 4,5 & Tibasosa & 2,6 & Chivor & 1,4 \\
\hline Berbeo & 1,6 & $\begin{array}{l}\text { San Miguel de } \\
\text { Sema }\end{array}$ & 3,0 & Santa María & 5,0 & Paipa & 2,6 & Iza & 1,6 \\
\hline San Eduardo & 1,7 & Villa de Leyva & 3,0 & Tunja & 6,9 & Oicatá & 2,9 & Pisba & 1,7 \\
\hline Tununguá & 1,7 & Miraflores & 3,3 & Macanal & 8,4 & Sogamoso & 3,0 & Guateque & 1,7 \\
\hline Sativasur & 1,7 & Santa María & 3,4 & Paya & 8,7 & Iza & 3,2 & Oicatá & 1,8 \\
\hline Panqueba & 1,8 & Paipa & 3,5 & Paipa & 8,8 & Chiquinquirá & 3,2 & Miraflores & 1,8 \\
\hline Macanal & 1,9 & Santa Sofia & 3,8 & Duitama & 9,5 & Duitama & 3,2 & Santa María & 1,9 \\
\hline Páez & 1,9 & Sogamoso & 3,8 & Sogamoso & 9,9 & Sotaquirá & 3,3 & Zetaquira & 1,9 \\
\hline Almeida & 2,0 & Páez & 3,9 & $\begin{array}{l}\text { San Luis de } \\
\text { Gaceno }\end{array}$ & 11,4 & Arcabuco & 3,4 & Villa de Leyva & 1,9 \\
\hline Cuítiva & 2,0 & Duitama & 3,9 & Corrales & 13,9 & Santa María & 3,6 & $\begin{array}{l}\text { San Miguel de } \\
\text { Sema }\end{array}$ & 2,0 \\
\hline Santa Sofía & 2,1 & Iza & 4,3 & Pisba & 17,5 & Tuta & 3,9 & Corrales & 2,1 \\
\hline Iza & 2,1 & Chiquinquirá & 4,6 & Almeida & 20,4 & Guateque & 4,0 & Otanche & 2,3 \\
\hline Tutasá & 2,1 & Arcabuco & 4,8 & Campohermoso & 20,7 & Saboyá & 4,0 & Macanal & 2,3 \\
\hline Beteitiva & 2,1 & Guateque & 5,2 & Chiquinquirá & 20,8 & Moniquirá & 4,2 & Puerto Boyacá & 2,5 \\
\hline Puerto Boyacá & 2,2 & Campohermoso & 5,4 & Paz del Río & 21,1 & Firavitoba & 4,3 & Berbeo & 2,6 \\
\hline Santa María & 2,2 & Santana & 5,6 & Guateque & 22,0 & Gachantivá & 4,3 & $\begin{array}{l}\text { San Luis de } \\
\text { Gaceno }\end{array}$ & 2,6 \\
\hline Campohermoso & 2,2 & Zetaquira & 5,6 & Chivor & 24,6 & Pachavita & 4,4 & San Eduardo & 2,6 \\
\hline Briceño & 2,2 & Boyacá & 5,7 & Villa de Leyva & 24,8 & Garagoa & 4,6 & Busbanzá & 2,7 \\
\hline Oicatá & 2,2 & Ventaquemada & 5,9 & Páez & 25,2 & Puerto Boyacá & 4,7 & Sora & 2,8 \\
\hline Sora & 2,2 & $\begin{array}{l}\text { San Luis de } \\
\text { Gaceno }\end{array}$ & 6,0 & $\begin{array}{l}\text { Santa Rosa de } \\
\text { Viterbo }\end{array}$ & 25,7 & Chinavita & 4,8 & Moniquirá & 2,9 \\
\hline
\end{tabular}




\begin{tabular}{|c|c|c|c|c|c|c|c|c|c|}
\hline Entidad & Total & Entidad & $\begin{array}{l}\text { Tribu- } \\
\text { tarios }\end{array}$ & Entidad & ICA & Entidad & Predial & Entidad & $\begin{array}{l}\text { No Tri- } \\
\text { butarios }\end{array}$ \\
\hline Guacamayas & 2,3 & Jenesano & 6,4 & Berbeo & 26,3 & Boyacá & 4,8 & Toguí & 3,0 \\
\hline Pajarito & 2,3 & Macanal & 6,5 & Oicatá & 27,5 & Toguí & 5,0 & Boyacá & 3,1 \\
\hline Corrales & 2,3 & Samacá & 6,8 & Busbanzá & 28,6 & Samacá & 5,1 & La Uvita & 3,1 \\
\hline Nobsa & 2,3 & Sáchica & 7,1 & Tununguá & 29,3 & Santana & 5,2 & Ramiriquí & 3,2 \\
\hline Sativanorte & 2,3 & Cómbita & 7,1 & Sativasur & 31,0 & Tinjacá & 5,3 & Sativasur & 3,2 \\
\hline Gachantivá & 2,4 & Moniquirá & 7,1 & San Eduardo & 31,3 & Sutatenza & 5,3 & \begin{tabular}{|l|} 
Tunja \\
\end{tabular} & 3,3 \\
\hline Covarachía & 2,4 & Cubará & 7,2 & La Victoria & 31,8 & Úmbita & 5,3 & Pachavita & 3,3 \\
\hline Tinjacá & 2,5 & Garagoa & 7,3 & Pajarito & 34,1 & La Capilla & 5,3 & Tenza & 3,3 \\
\hline Viracachá & 2,5 & Oicatá & 7,9 & Cómbita & 34,6 & $\begin{array}{l}\text { Santa Rosa } \\
\text { de Viterbo }\end{array}$ & 5,4 & Jenesano & 3,4 \\
\hline La Uvita & 2,6 & $\begin{array}{l}\text { Santa Rosa } \\
\text { de Viterbo }\end{array}$ & 8,0 & Santa Sofia & 36,3 & Aquitania & 5,5 & Tuta & 3,4 \\
\hline Coper & 2,6 & Corrales & 8,1 & Samacá & 36,6 & Berbeo & 5,5 & Sáchica & 3,5 \\
\hline Rondón & 2,7 & Paya & 8,4 & Garagoa & 38,9 & Tenza & 5,6 & Nobsa & 3,5 \\
\hline Zetaquira & 2,7 & Sotaquirá & 8,6 & Beteitiva & 44,2 & Toca & 5,6 & Almeida & 3,8 \\
\hline Tuta & 2,7 & Paz del Río & 8,8 & Arcabuco & 45,9 & Sutamarchan & 5,6 & \begin{tabular}{|l|} 
Chinavita \\
\end{tabular} & 3,8 \\
\hline $\begin{array}{l}\text { San Miguel } \\
\text { de Sema }\end{array}$ & 2,7 & Chivor & 8,8 & Ventaquemada & 48,3 & Jenesano & 5,7 & Panqueba & 3,8 \\
\hline Tipacoque & 2,7 & Saboyá & 8,9 & Sáchica & 50,3 & Viracacha & 5,7 & Ciénega & 3,9 \\
\hline Pachavita & 2,7 & Sutamarchán & 8,9 & Coper & 50,7 & Nuevo Colon & 6,2 & Chiquinquirá & 4,1 \\
\hline Chinavita & 2,8 & Belén & 8,9 & Tópaga & 51,1 & $\begin{array}{l}\text { San Jose } \\
\text { de Pare }\end{array}$ & 6,2 & Garagoa & 4,1 \\
\hline Boyacá & 2,8 & Ramiriquí & 9,2 & Guacamayas & 54,6 & Soraca & 6,3 & Tibaná & 4,1 \\
\hline San Mateo & 2,8 & Tinjacá & 9,6 & Tota & 55,0 & Cuitiva & 6,3 & Paz del Río & 4,2 \\
\hline Jerico & 2,9 & Cucaita & 9,6 & $\begin{array}{l}\text { San Miguel de } \\
\text { Sema }\end{array}$ & 55,4 & $\begin{array}{l}\text { San Luis de } \\
\text { Gaceno }\end{array}$ & 6,4 & Úmbita & 4,3 \\
\hline \begin{tabular}{|l|} 
Jenesano \\
\end{tabular} & 2,9 & Firavitoba & 9,8 & Iza & 55,6 & Caldas & 6,4 & Gachantivá & 4,3 \\
\hline \begin{tabular}{|l|} 
El Espino \\
\end{tabular} & 2,9 & Caldas & 9,9 & Otanche & 59,7 & Paz Del Rio & 6,4 & Gameza & 4,3 \\
\hline Arcabuco & 3,0 & Toca & 10,0 & Sutamarchán & 60,0 & Siachoque & 6,4 & Buenavista & 4,3 \\
\hline Susacón & 3,0 & Chinavita & 10,3 & Zetaquira & 62,1 & El Cocuy & 6,4 & Chiscas & 4,4 \\
\hline Miraflores & 3,0 & Gachantivá & 10,3 & Muzo & 63,4 & Cienega & 6,6 & Muzo & 4,4 \\
\hline
\end{tabular}




\begin{tabular}{|c|c|c|c|c|c|c|c|c|c|}
\hline Entidad & Total & Entidad & $\begin{array}{l}\text { Tribu- } \\
\text { tarios }\end{array}$ & Entidad & ICA & Entidad & Predial & Entidad & $\begin{array}{c}\text { No Tri- } \\
\text { butarios }\end{array}$ \\
\hline Labranzagrande & 3,0 & Tenza & 10,4 & Sotaquirá & 63,9 & El Espino & 6,8 & Paya & 4,4 \\
\hline La Capilla & 3,0 & Busbanzá & 10,4 & Moniquirá & 65,7 & Campohermoso & 6,8 & Tinjacá & 4,5 \\
\hline Sáchica & 3,1 & Berbeo & 10,7 & Gachantivá & 65,9 & Turmeque & 6,8 & Socha & 4,6 \\
\hline El Cocuy & 3,1 & Pachavita & 11,0 & Santana & 68,9 & Chiscas & 7,0 & Soracá & 4,7 \\
\hline Otanche & 3,1 & Aquitania & 11,2 & Sutatenza & 70,3 & Corrales & 7,1 & Tutasá & 4,7 \\
\hline Cubará & 3,1 & Pisba & 11,4 & Tutasá & 72,7 & Ramiriqui & 7,1 & Briceño & 4,7 \\
\hline Santana & 3,1 & Otanche & 11,9 & Briceño & 72,8 & Ventaquemada & 7,1 & Turmeque & 4,8 \\
\hline Chiscas & 3,1 & La Capilla & 12,0 & Socha & 73,5 & Santa Sofia & 7,3 & Pajarito & 4,8 \\
\hline Tópaga & 3,1 & Toguí & 12,0 & Sora & 76,6 & San Eduardo & 7,4 & Chivatá & 4,9 \\
\hline Toguí & 3,1 & Pajarito & 12,1 & Ramiriquí & 78,0 & Cubara & 7,4 & La Capilla & 5,0 \\
\hline Paipa & 3,2 & Almeida & 12,1 & Jenesano & 81,2 & Miraflores & 7,5 & Cubará & 5,1 \\
\hline Somondoco & 3,2 & El Cocuy & 12,3 & Cuitiva & 81,6 & Zetaquira & 7,6 & Sutamarchán & 5,1 \\
\hline Caldas & 3,2 & San Eduardo & 12,4 & Cerinza & 85,1 & Guacamayas & 7,6 & El Cocuy & 5,1 \\
\hline Buenavista & 3,2 & Sutatenza & 12,4 & Pesca & 87,8 & Somondoco & 7,6 & \begin{tabular}{|l|} 
Tópaga \\
\end{tabular} & 5,1 \\
\hline Sutatenza & 3,3 & Cuitiva & 13,0 & Belén & 89,9 & Sora & 7,7 & Viracachá & 5,2 \\
\hline Maripí & 3,3 & Turmequé & 13,2 & Tenza & 91,6 & Chitaraque & 7,9 & \begin{tabular}{|l|} 
Cuitiva \\
\end{tabular} & 5,2 \\
\hline $\begin{array}{l}\text { San Luis } \\
\text { de Gaceno }\end{array}$ & 3,3 & $\begin{array}{l}\text { San José } \\
\text { de Pare }\end{array}$ & 13,8 & Ciénega & 93,4 & Belen & 8,1 & Guayatá & 5,2 \\
\hline Chitaraque & 3,4 & Nuevo Colón & 14,1 & Pachavita & 93,9 & La Uvita & 8,1 & Samacá & 5,3 \\
\hline Cucaita & 3,4 & Soracá & 14,1 & Boyacá & 94,6 & Pesca & 8,1 & El Espino & 5,4 \\
\hline Paz del Río & 3,4 & Úmbita & 14,3 & Guayatá & 95,4 & Panqueba & 8,3 & Beteitiva & 5,4 \\
\hline Villa de Leyva & 3,5 & Viracachá & 14,3 & Panqueba & 95,5 & Cerinza & 8,5 & Somondoco & 5,4 \\
\hline Sutamarchán & 3,5 & Siachoque & 14,6 & Covarachía & 96,8 & Combita & 8,6 & San Mateo & 5,5 \\
\hline Ciénega & 3,5 & Muzo & 15,0 & Soracá & 100,4 & Cucaita & 8,8 & Sutatenza & 5,5 \\
\hline Tenza & 3,6 & Socha & 15,0 & Somondoco & 100,8 & Almeida & 8,9 & Arcabuco & 5,6 \\
\hline Tibasosa & 3,6 & Briceño & 15,3 & Viracachá & 101,2 & Chiquiza & 9,0 & Chíquiza & 5,6 \\
\hline Quípama & 3,6 & Chitaraque & 15,3 & Quípama & 101,3 & Macanal & 9,1 & Siachoque & 5,7 \\
\hline Guateque & 3,7 & Tutasá & 15,4 & Cubará & 102,5 & Busbanza & 9,1 & Duitama & 5,7 \\
\hline Gámeza & 3,7 & Cerinza & 15,6 & El Cocuy & 103,3 & Tibana & 9,1 & Aquitania & 5,9 \\
\hline Floresta & 3,7 & Pesca & 15,8 & Soatá & 103,6 & Briceño & 9,5 & Santana & 6,0 \\
\hline Mongua & 3,8 & Coper & 15,8 & Chitaraque & 106,7 & San Mateo & 9,6 & Tibasosa & 6,0 \\
\hline
\end{tabular}




\begin{tabular}{|c|c|c|c|c|c|c|c|c|c|}
\hline Entidad & Total & Entidad & $\begin{array}{l}\text { Tribu- } \\
\text { tarios }\end{array}$ & Entidad & ICA & Entidad & Predial & Entidad & $\begin{array}{l}\text { No Tri- } \\
\text { butarios }\end{array}$ \\
\hline Soracá & 3,8 & Sora & 16,1 & Ráquira & 107,9 & Sáchica & 9,7 & Firavitoba & 6,1 \\
\hline Tota & 3,8 & Ciénega & 16,1 & Gámeza & 110,1 & Coper & 9,7 & Belén & 6,1 \\
\hline $\begin{array}{l}\text { San Jose } \\
\text { de Pare }\end{array}$ & 3,8 & Somondoco & 16,3 & Pauna & 110,2 & Rondon & 9,7 & Saboyá & 6,2 \\
\hline Tunja & 3,9 & Soatá & 16,5 & La Capilla & 110,6 & Tutasa & 10,2 & Tununguá & 6,2 \\
\hline Pauna & 3,9 & Tibaná & 16,5 & Sativanorte & 110,6 & Mongui & 10,4 & Toca & 6,3 \\
\hline Cerinza & 3,9 & El Espino & 17,0 & Tinjacá & 112,3 & Paez & 10,6 & Cucaita & 6,4 \\
\hline Chivatá & 4,0 & Guacamayas & 17,1 & Chíquiza & 113,7 & Guayata & 10,8 & $\begin{array}{l}\text { Santa Rosa } \\
\text { de Viterbo }\end{array}$ & 6,4 \\
\hline Chíquiza & 4,0 & La Victoria & 17,3 & Nuevo Colón & 113,7 & Chivor & 11,0 & Móngua & 6,6 \\
\hline Tibaná & 4,1 & Buenavista & 17,7 & Jerico & 113,9 & Motavita & 11,0 & Guacamayas & 6,7 \\
\hline Chita & 4,1 & La Uvita & 18,1 & Labranzagrande & 118,1 & Socha & 11,1 & Tasco & 6,7 \\
\hline Muzo & 4,1 & Chiscas & 18,5 & Chivatá & 118,7 & Sativasur & 11,8 & Quípama & 6,9 \\
\hline Soatá & 4,1 & Tununguá & 18,5 & La Uvita & 126,3 & Chivata & 12,1 & Sativanorte & 7,1 \\
\hline Ramiriquí & 4,2 & Pauna & 19,7 & Rondón & 130,4 & Soata & 12,3 & Pauna & 7,1 \\
\hline Nuevo Colón & 4,2 & Panqueba & 20,3 & Aquitania & 135,8 & Gameza & 12,5 & Coper & 7,2 \\
\hline Socotá & 4,2 & Tota & 20,3 & Socotá & 136,2 & Sativanorte & 12,5 & Boavita & 7,5 \\
\hline Socha & 4,3 & Beteitiva & 20,4 & Maripí & 136,9 & Raquira & 12,6 & Jerico & 7,5 \\
\hline Tasco & 4,3 & Rondón & 20,9 & Caldas & 136,9 & Pajarito & 12,7 & Caldas & 7,7 \\
\hline Siachoque & 4,3 & Tópaga & 21,0 & Cucaita & 140,1 & Susacon & 12,7 & La Victoria & 7,8 \\
\hline Saboyá & 4,3 & Guayatá & 21,0 & $\begin{array}{l}\text { San Pablo } \\
\text { de Borbur }\end{array}$ & 141,7 & Tópaga & 12,9 & Monguí & 7,8 \\
\hline Úmbita & 4,4 & San Mateo & 21,2 & Saboyá & 142,7 & Tota & 13,1 & Nuevo Colón & 7,9 \\
\hline Firavitoba & 4,4 & Sativasur & 21,7 & Toguí & 152,6 & Buenavista & 13,8 & Chitaraque & 7,9 \\
\hline Guayatá & 4,4 & Labranzagrande & 22,5 & Buenavista & 153,1 & Mongua & 14,0 & Tota & 8,0 \\
\hline Guicán & 4,5 & Monguí & 23,1 & El Espino & 153,6 & Floresta & 14,8 & Rondón & 8,2 \\
\hline Belén & 4,5 & Sativanorte & 23,1 & Chinavita & 159,5 & Labranzagrande & 15,4 & Ventaquemada & 8,3 \\
\hline Samacá & 4,6 & Ráquira & 25,0 & Monguí & 160,8 & Pauna & 15,4 & Sogamoso & 8,3 \\
\hline Aquitania & 4,6 & Susacón & 25,1 & Turmequé & 169,7 & Covarachia & 15,4 & Soatá & 8,3 \\
\hline Ventaquemada & 4,6 & Chíquiza & 25,3 & Tasco & 169,9 & Tunungua & 15,5 & $\begin{array}{l}\text { San José } \\
\text { de Pare }\end{array}$ & 8,3 \\
\hline
\end{tabular}




\begin{tabular}{|c|c|c|c|c|c|c|c|c|c|}
\hline Entidad & Total & Entidad & $\begin{array}{l}\text { Tribu- } \\
\text { tarios }\end{array}$ & Entidad & ICA & Entidad & Predial & Entidad & $\begin{array}{l}\text { No Tri- } \\
\text { butarios }\end{array}$ \\
\hline Duitama & 4,6 & Motavita & 25,7 & Tibaná & 174,2 & Tasco & 16,4 & Susacón & 8,4 \\
\hline Motavita & 4,7 & Gámeza & 26,0 & Tipacoque & 176,5 & Otanche & 17,3 & Sotaquirá & 9,1 \\
\hline Monguí & 4,7 & Chivatá & 27,8 & Floresta & 179,1 & Muzo & 17,5 & Ráquira & 10,3 \\
\hline Sogamoso & 4,7 & Maripí & 30,2 & Siachoque & 182,7 & Guican & 17,5 & Covarachía & 10,4 \\
\hline Boavita & 4,7 & Tipacoque & 32,0 & Motavita & 184,8 & Beteitiva & 18,2 & Tipacoque & 10,4 \\
\hline Garagoa & 4,7 & Boavita & 33,2 & Toca & 199,9 & Tipacoque & 20,0 & Floresta & 12,4 \\
\hline $\begin{array}{l}\text { San Pablo } \\
\text { de Borbur }\end{array}$ & 4,8 & Floresta & 33,3 & Móngua & 210,2 & Chita & 20,2 & Cerinza & 12,6 \\
\hline Sotaquirá & 4,9 & Socotá & 34,4 & Guicán & 216,0 & Boavita & 21,1 & Pesca & 13,2 \\
\hline Toca & 4,9 & Jericó & 34,8 & Chiscas & 216,3 & Maripi & 22,5 & Guicán & 13,4 \\
\hline Turmequé & 4,9 & Mongua & 35,1 & Susacón & 225,0 & Jerico & 28,2 & Cómbita & 13,6 \\
\hline Moniquirá & 5,0 & Quípama & 35,3 & San Mateo & 229,6 & Socota & 30,3 & Motavita & 14,7 \\
\hline Pesca & 5,0 & Guicán & 37,3 & Firavitoba & 235,5 & Pisba & 37,7 & Labranzagrande & 14,8 \\
\hline Cómbita & 5,2 & Tasco & 37,8 & $\begin{array}{l}\text { San Jose } \\
\text { de Pare }\end{array}$ & 263,7 & La Victoria & 38,7 & \begin{tabular}{|l|l|} 
Chita \\
\end{tabular} & 15,2 \\
\hline $\begin{array}{l}\text { Santa Rosa } \\
\text { de Viterbo }\end{array}$ & 5,9 & Covarachia & 37,8 & Chita & 278,7 & Paya & 45,0 & Maripí & 15,2 \\
\hline Chiquinquirá & 5,9 & $\begin{array}{l}\text { San Pablo } \\
\text { de Borbur }\end{array}$ & 39,3 & Boavita & 325,5 & $\begin{array}{l}\text { San Pablo de } \\
\text { Borbur }\end{array}$ & 45,1 & Socotá & 15,6 \\
\hline Ráquira & 5,9 & Chita & 41,9 & Úmbita & 538,0 & Quipama & 61,0 & $\begin{array}{l}\text { San Pablo } \\
\text { de Borbur }\end{array}$ & 20,6 \\
\hline
\end{tabular}

Fuente: cálculos del autor con base en las ejecuciones presupuestales del DNP, varios años. 
Anexo 2. Municipios de Boyacá. Indicadores de bienestar 1993 y 2005.

\begin{tabular}{|c|c|c|c|c|c|c|c|}
\hline \multirow[t]{2}{*}{ Municipio } & \multirow[t]{2}{*}{ Provincia } & \multicolumn{2}{|c|}{$\%$ Personas en NBI } & \multicolumn{2}{|c|}{ Gini de gastos } & \multicolumn{2}{|c|}{ \% Pobreza } \\
\hline & & 1993 & 2005 & 1993 & 2005 & 1993 & 2005 \\
\hline Almeida & Oriente & 46,87 & 37,32 & 0,47 & 0,43 & 71,0 & 49,0 \\
\hline Aquitania & Sugamuxi & 53,00 & 42,76 & 0,45 & 0,41 & 57,0 & 52,0 \\
\hline Arcabuco & Ricaurte & 40,63 & 33,25 & 0,47 & 0,42 & 65,0 & 47,0 \\
\hline Belén & Tundama & 41,99 & 31,06 & 0,45 & 0,42 & 57,0 & 40,0 \\
\hline Berbeo & Lengupá & 64,90 & 36,12 & 0,46 & 0,42 & 40,0 & 47,0 \\
\hline Beteitiva & Valderrama & 57,08 & 64,02 & 0,44 & 0,39 & 76,0 & 53,0 \\
\hline Boavita & Norte & 51,33 & 52,88 & 0,49 & 0,44 & 79,0 & 50,0 \\
\hline Boyacá & Márquez & 53,79 & 51,01 & 0,43 & 0,41 & 75,0 & 54,0 \\
\hline Briceño & Occidente & 54,06 & 35,02 & 0,50 & 0,42 & 73,0 & 49,0 \\
\hline Buenavista & Occidente & 58,38 & 45,04 & 0,47 & 0,40 & 62,0 & 52,0 \\
\hline Busbanzá & Tundama & 50,00 & 57,97 & 0,48 & 0,43 & 70,0 & 48,0 \\
\hline Caldas & Occidente & 43,67 & 39,04 & 0,48 & 0,41 & 63,0 & 51,0 \\
\hline Campohermoso & Lengupá & 55,84 & 44,05 & 0,47 & 0,43 & 65,0 & 55,0 \\
\hline Cerinza & Tundama & 33,80 & 26,02 & 0,44 & 0,40 & 59,0 & 43,0 \\
\hline Chinavitá & Neira & 31,32 & 35,79 & 0,44 & 0,43 & 60,0 & 46,0 \\
\hline Chiquinquirá & Occidente & 28,17 & 17,87 & 0,46 & 0,40 & 47,0 & 34,0 \\
\hline Chíquiza & Centro & 60,11 & 49,00 & 0,45 & 0,39 & 82,0 & 56,0 \\
\hline Chiscas & Gutiérrez & 59,13 & 69,98 & 0,47 & 0,42 & 74,0 & 48,0 \\
\hline Chita & Valderrama & 69,66 & 81,22 & 0,46 & 0,45 & 76,0 & 61,0 \\
\hline Chitaraque & Ricaurte & 62,15 & 47,31 & 0,50 & 0,43 & 73,0 & 54,0 \\
\hline Chivatá & Centro & 43,23 & 49,37 & 0,45 & 0,38 & 80,0 & 56,0 \\
\hline Chivor & Oriente & 46,34 & 34,16 & 0,46 & 0,40 & 65,0 & 49,0 \\
\hline Ciénega & Márquez & 43,33 & 29,81 & 0,47 & 0,40 & 67,0 & 48,0 \\
\hline Cómbita & Centro & 38,29 & 38,40 & 0,48 & 0,41 & 70,0 & 47,0 \\
\hline Coper & Occidente & 58,97 & 47,03 & 0,49 & 0,43 & 67,0 & 55,0 \\
\hline Corrales & Tundama & 39,49 & 27,95 & 0,45 & 0,40 & 70,0 & 64,0 \\
\hline Covarachía & Norte & 73,31 & 79,65 & 0,45 & 0,41 & 64,0 & 48,0 \\
\hline Cubará & Dist. Fronterizo & 78,41 & 58,46 & 0,47 & 0,48 & 58,0 & 52,0 \\
\hline Cucaita & Centro & 49,12 & 42,91 & 0,50 & 0,39 & 74,0 & 48,0 \\
\hline Cuítiva & Sugamuxi & 34,62 & 46,19 & 0,45 & 0,41 & 69,0 & 52,0 \\
\hline
\end{tabular}




\begin{tabular}{|c|c|c|c|c|c|c|c|}
\hline \multirow[t]{2}{*}{ Municipio } & \multirow[t]{2}{*}{ Provincia } & \multicolumn{2}{|c|}{ \% Personas en NBI } & \multicolumn{2}{|c|}{ Gini de gastos } & \multicolumn{2}{|c|}{ \% Pobreza } \\
\hline & & 1993 & 2005 & 1993 & 2005 & 1993 & 2005 \\
\hline Duitama & Tundama & 16,58 & 8,99 & 0,46 & 0,40 & 41,0 & 28,0 \\
\hline El Cocuy & Gutiérrez & 58,00 & 54,67 & 0,46 & 0,41 & 61,0 & 50,0 \\
\hline El Espino & Gutiérrez & 46,50 & 51,35 & 0,45 & 0,42 & 62,0 & 50,0 \\
\hline Firavitoba & Sugamuxi & 33,95 & 27,59 & 0,46 & 0,42 & 61,0 & 42,0 \\
\hline Floresta & Tundama & 46,53 & 46,14 & 0,46 & 0,41 & 68,0 & 42,0 \\
\hline Gachantivá & Ricaurte & 55,38 & 60,35 & 0,47 & 0,42 & 75,0 & 53,0 \\
\hline Gámeza & Sugamuxi & 47,00 & 44,19 & 0,42 & 0,39 & 75,0 & 48,0 \\
\hline Garagoa & Neira & 26,74 & 23,06 & 0,45 & 0,41 & 50,0 & 42,0 \\
\hline Guacamayas & Gutiérrez & 44,51 & 62,69 & 0,47 & 0,44 & 69,0 & 48,0 \\
\hline Guateque & Oriente & 25,30 & 25,96 & 0,45 & 0,42 & 50,0 & 45,0 \\
\hline Guayatá & Oriente & 32,39 & 48,08 & 0,42 & 0,43 & 68,0 & 45,0 \\
\hline Güicán & Gutiérrez & 61,08 & 68,54 & 0,46 & 0,50 & 61,0 & 64,0 \\
\hline Iza & Sugamuxi & 30,12 & 23,22 & 0,46 & 0,42 & 63,0 & 42,0 \\
\hline Jenesano & Márquez & 46,68 & 41,83 & 0,45 & 0,42 & 67,0 & 52,0 \\
\hline Jerico & Valderrama & 69,88 & 74,00 & 0,45 & 0,41 & 71,0 & 53,0 \\
\hline La Capilla & Oriente & 34,58 & 25,30 & 0,41 & 0,41 & 52,0 & 45,0 \\
\hline La Uvita & Norte & 50,50 & 49,63 & 0,50 & 0,43 & 69,0 & 48,0 \\
\hline La Victoria & Occidente & 71,02 & 44,74 & 0,44 & 0,41 & 63,0 & 54,0 \\
\hline Labranzagrande & La Libertad & 81,18 & 70,15 & 0,44 & 0,45 & 53,0 & 63,0 \\
\hline Macanal & Neira & 44,13 & 35,23 & 0,47 & 0,42 & 57,0 & 48,0 \\
\hline Maripí & Occidente & 76,36 & 47,63 & 0,50 & 0,41 & 68,0 & 59,0 \\
\hline Miraflores & Lengupá & 34,72 & 25,35 & 0,47 & 0,42 & 52,0 & 46,0 \\
\hline Móngua & Sugamuxi & 49,68 & 47,14 & 0,43 & 0,40 & 67,0 & 51,0 \\
\hline Monguí & Sugamuxi & 29,46 & 30,14 & 0,44 & 0,40 & 63,0 & 44,0 \\
\hline Moniquirá & Ricaurte & 41,43 & 30,88 & 0,50 & 0,45 & 59,0 & 46,0 \\
\hline Motavita & Centro & 41,62 & 50,19 & 0,45 & 0,38 & 76,0 & 52,0 \\
\hline Muzo & Occidente & 49,09 & 45,67 & 0,52 & 0,42 & 54,0 & 58,0 \\
\hline Nobsa & Sugamuxi & 14,40 & 13,54 & 0,46 & 0,39 & 37,0 & 27,0 \\
\hline Nuevo Colón & Márquez & 39,57 & 28,48 & 0,46 & 0,40 & 67,0 & 47,0 \\
\hline Oicatá & Centro & 39,43 & 51,64 & 0,48 & 0,41 & 74,0 & 47,0 \\
\hline Otanche & Occidente & 60,84 & 50,66 & 0,51 & 0,43 & 52,0 & 63,0 \\
\hline Pachavita & Neira & 49,26 & 37,00 & 0,45 & 0,42 & 58,0 & 47,0 \\
\hline
\end{tabular}




\begin{tabular}{|c|c|c|c|c|c|c|c|}
\hline \multirow[t]{2}{*}{ Municipio } & \multirow[t]{2}{*}{ Provincia } & \multicolumn{2}{|c|}{$\%$ Personas en NBI } & \multicolumn{2}{|c|}{ Gini de gastos } & \multicolumn{2}{|c|}{ \% Pobreza } \\
\hline & & 1993 & 2005 & 1993 & 2005 & 1993 & 2005 \\
\hline Páez & Lengupá & 48,06 & 38,15 & 0,48 & 0,42 & 65,0 & 53,0 \\
\hline Paipa & Tundama & 24,41 & 18,07 & 0,48 & 0,42 & 54,0 & 36,0 \\
\hline Pajarito & La Libertad & 51,06 & 41,63 & 0,47 & 0,41 & 60,0 & 55,0 \\
\hline Panqueba & Gutiérrez & 54,72 & 46,93 & 0,47 & 0,42 & 70,0 & 46,0 \\
\hline Pauna & Occidente & 59,21 & 61,74 & 0,48 & 0,44 & 67,0 & 63,0 \\
\hline Paya & La Libertad & 91,10 & 82,42 & 0,46 & 0,43 & 77,0 & 63,0 \\
\hline Paz de Río & Valderrama & 32,25 & 27,61 & 0,51 & 0,41 & 58,0 & 41,0 \\
\hline Pesca & Sugamuxi & 49,03 & 50,12 & 0,49 & 0,41 & 76,0 & 49,0 \\
\hline Pisba & La Libertad & 84,54 & 80,77 & 0,46 & 0,44 & 70,0 & 69,0 \\
\hline Puerto Boyacá & Zona Manej. Espec. & 39,28 & 39,31 & 0,45 & 0,42 & 50,0 & 45,0 \\
\hline Quípama & Occidente & 58,17 & 53,78 & 0,51 & 0,43 & 57,0 & 60,0 \\
\hline Ramiriquí & Márquez & 50,89 & 41,51 & 0,48 & 0,43 & 72,0 & 51,0 \\
\hline Ráquira & Ricaurte & 64,92 & 60,22 & 0,47 & 0,41 & 66,0 & 57,0 \\
\hline Rondón & Márquez & 52,13 & 41,71 & 0,46 & 0,42 & 66,0 & 52,0 \\
\hline Saboyá & Occidente & 60,65 & 49,19 & 0,50 & 0,43 & 70,0 & 55,0 \\
\hline Sáchica & Ricaurte & 44,38 & 46,08 & 0,47 & 0,43 & 61,0 & 49,0 \\
\hline Samacá & Centro & 40,31 & 30,86 & 0,48 & 0,40 & 65,0 & 46,0 \\
\hline San Eduardo & Lengupá & 53,01 & 30,72 & 0,48 & 0,42 & 58,0 & 50,0 \\
\hline San José de Pare & Ricaurte & 41,71 & 44,83 & 0,45 & 0,41 & 77,0 & 55,0 \\
\hline San Luis de Gaceno & Neira & 52,93 & 33,53 & 0,49 & 0,43 & 60,0 & 55,0 \\
\hline San Mateo & Norte & 57,04 & 52,08 & 0,47 & 0,43 & 70,0 & 49,0 \\
\hline San Miguel de Sema & Occidente & 35,24 & 31,44 & 0,48 & 0,41 & 63,0 & 49,0 \\
\hline San Pablo de Borbur & Occidente & 51,36 & 46,72 & 0,51 & 0,40 & 63,0 & 58,0 \\
\hline Santa María & Neira & 47,13 & 32,73 & 0,46 & 0,42 & 49,0 & 49,0 \\
\hline Santa Rosa de Viterbo & Tundama & 29,66 & 17,14 & 0,47 & 0,41 & 48,0 & 36,0 \\
\hline Santa Sofía & Ricaurte & 47,03 & 35,81 & 0,49 & 0,44 & 60,0 & 45,0 \\
\hline Santana & Ricaurte & 40,87 & 42,46 & 0,49 & 0,43 & 69,0 & 55,0 \\
\hline Sativanorte & Norte & 57,22 & 60,40 & 0,47 & 0,43 & 61,0 & 50,0 \\
\hline Sativasur & Norte & 39,99 & 46,14 & 0,48 & 0,43 & 66,0 & 46,0 \\
\hline Siachoque & Centro & 50,58 & 50,80 & 0,49 & 0,40 & 76,0 & 51,0 \\
\hline Soatá & Norte & 54,00 & 40,11 & 0,43 & 0,43 & 55,0 & 42,0 \\
\hline Socha & Valderrama & 38,77 & 29,14 & 0,46 & 0,41 & 61,0 & 45,0 \\
\hline
\end{tabular}




\begin{tabular}{|c|c|c|c|c|c|c|c|}
\hline \multirow[t]{2}{*}{ Municipio } & \multirow[t]{2}{*}{ Provincia } & \multicolumn{2}{|c|}{ \% Personas en NBI } & \multicolumn{2}{|c|}{ Gini de gastos } & \multicolumn{2}{|c|}{ \% Pobreza } \\
\hline & & 1993 & 2005 & 1993 & 2005 & 1993 & 2005 \\
\hline Socotá & Valderrama & 70,09 & 72,35 & 0,45 & 0,42 & 76,0 & 57,0 \\
\hline Sogamoso & Sugamuxi & 20,74 & 11,60 & 0,45 & 0,41 & 39,0 & 32,0 \\
\hline Somondoco & Oriente & 43,60 & 36,90 & 0,46 & 0,43 & 65,0 & 45,0 \\
\hline Sora & Centro & 48,40 & 46,30 & 0,48 & 0,42 & 76,0 & 52,0 \\
\hline Soracá & Centro & 54,35 & 46,26 & 0,47 & 0,40 & 79,0 & 52,0 \\
\hline Sotaquirá & Centro & 36,54 & 37,48 & 0,46 & 0,41 & 64,0 & 48,0 \\
\hline Susacon & Norte & 60,99 & 55,95 & 0,45 & 0,42 & 60,0 & 52,0 \\
\hline Sutamarchán & Ricaurte & 60,02 & 35,38 & 0,44 & 0,42 & 55,0 & 46,0 \\
\hline Sutatenza & Oriente & 39,02 & 57,70 & 0,45 & 0,43 & 67,0 & 52,0 \\
\hline Tasco & Valderrama & 41,78 & 39,49 & 0,44 & 0,41 & 70,0 & 45,0 \\
\hline Tenza & Oriente & 29,76 & 28,23 & 0,46 & 0,42 & 57,0 & 48,0 \\
\hline Tibaná & Márquez & 50,25 & 45,90 & 0,45 & 0,42 & 71,0 & 51,0 \\
\hline Tibasosa & Sugamuxi & 22,17 & 16,18 & 0,46 & 0,42 & 54,0 & 37,0 \\
\hline Tinjacá & Ricaurte & 58,83 & 48,03 & 0,48 & 0,43 & 52,0 & 48,0 \\
\hline Tipacoque & Norte & 66,25 & 63,14 & 0,44 & 0,43 & 62,0 & 55,0 \\
\hline Toca & Centro & 43,86 & 44,45 & 0,50 & 0,41 & 68,0 & 50,0 \\
\hline Togüí & Ricaurte & 54,64 & 44,00 & 0,53 & 0,42 & 69,0 & 52,0 \\
\hline Tópaga & Sugamuxi & 34,95 & 29,40 & 0,42 & 0,40 & 66,0 & 45,0 \\
\hline Tota & Sugamuxi & 49,35 & 60,64 & 0,44 & 0,40 & 74,0 & 57,0 \\
\hline Tunja & Centro & 19,39 & 12,01 & 0,47 & 0,41 & 39,0 & 27,0 \\
\hline Tununguá & Occidente & 58,87 & 22,67 & 0,45 & 0,43 & 58,0 & 50,0 \\
\hline Turmequé & Márquez & 38,81 & 32,11 & 0,44 & 0,42 & 67,0 & 46,0 \\
\hline Tuta & Centro & 38,24 & 32,46 & 0,47 & 0,42 & 66,0 & 43,0 \\
\hline Tutazá & Tundama & 60,70 & 46,68 & 0,48 & 0,39 & 63,0 & 49,0 \\
\hline Úmbita & Márquez & 58,60 & 47,36 & 0,47 & 0,41 & 74,0 & 51,0 \\
\hline Ventaquemada & Centro & 38,20 & 28,45 & 0,47 & 0,39 & 66,0 & 46,0 \\
\hline Villa de Leyva & Ricaurte & 36,49 & 25,86 & 0,45 & 0,43 & 50,0 & 37,0 \\
\hline Viracachá & Márquez & 38,64 & 38,02 & 0,44 & 0,40 & 74,0 & 49,0 \\
\hline Zetaquira & Lengupá & 51,85 & 38,08 & 0,48 & 0,42 & 57,0 & 51,0 \\
\hline \multicolumn{2}{|l|}{ Promedio } & 47,94 & 42,62 & $\mathbf{0 , 4 7}$ & $\mathbf{0 , 4 2}$ & 63,81 & 49,23 \\
\hline
\end{tabular}

Fuente: cálculos del autor con base en las ejecuciones presupuestales del DNP, varios años. 
Anexo 3. Municipios de Boyacá. Índices de Theil intra provincias de los Ingresos Totales.

\begin{tabular}{|c|c|c|c|c|c|c|c|c|c|c|c|c|c|c|}
\hline Años & ن⿺辶 & نू & צ & 包 & 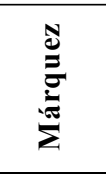 & Z & Z゙ & 䢘 & $\stackrel{\stackrel{0}{0}}{.0}$ & 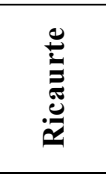 & 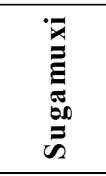 & $\underset{\Xi}{\stackrel{\Xi}{\Xi}}$ & 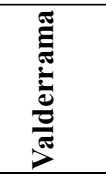 & 营 \\
\hline 1985 & 0,0059 & 0,0037 & 0,0002 & 0,0028 & 0,0005 & 0,0056 & 0,0048 & 0,0534 & 0,0020 & 0,0028 & 0,0217 & 0,0085 & 0,0014 & 0,113 \\
\hline 1986 & 064 & 025 & 0005 & 0012 & 0007 & 0,0037 & 0,0036 & 0,0508 & 0,0022 & 0040 & 0162 & 0028 &, 0014 & ,096 \\
\hline 1987 & 0,0050 & 0,0017 & 0,0014 & 0,0027 & 0,0010 & 0,0020 & 0,0047 & 0,0115 & 0,0005 & 0,0116 & 0,0320 & 0,0081 & 0,0046 & 0,087 \\
\hline 1988 & 0088 & 0,0018 & 0,0019 & 0,0065 & 0,0016 & 0,0024 & 0,0019 & 0,0147 & 0,0055 & 0,0052 & 0,0285 & 0,0237 & 0,0020 & 0,105 \\
\hline 1989 & 0,0137 & 0,0005 & 0,0019 & 0,0047 & 0,0009 & 0,0017 & 0,0014 & 0,0060 & 0,0059 & 0,0145 & 0,0198 & 0,0053 & 0,0007 & 0,077 \\
\hline 1990 & 0051 & 0,0003 & 0,0003 & 0,0007 & 0,0011 & 0,0005 & 0,0016 & 0,0046 & 0,0079 & 0,0038 & 0,0100 & 0,0034 & 0,0059 & 0,045 \\
\hline 1991 & 0,0019 & 0,0019 & 0,0004 & 0,0004 & 0,0032 & 0,0006 & 0,0019 & 0,0039 & 0,0037 & 0,0034 & 0,0069 & 0,0022 & 0,0042 & 0,034 \\
\hline 1992 & 0,0029 & 0,0006 & 0,0005 & 0,0007 & 0,0044 & 0,0004 & 0,0029 & 0,0038 & 0,0006 & 0,0161 & 0,0083 & 0,0012 & 0,0027 & 0,045 \\
\hline 1993 & 0,0042 & 0,0023 & 0,0026 & 0,0012 & 0,0025 & 0,0035 & 0,0027 & 0,0056 & 0,0046 & 0,0057 & 0,0065 & 0,0013 & 0,0015 & 0,044 \\
\hline 1994 & 0,0090 & 0,0025 & 0,0025 & 0,0011 & 0,0021 & 0,0107 & 0,0054 & 0,0125 & 0,0015 & 0,0040 & 0,0043 & 0,0019 & 0,0011 & 0,059 \\
\hline 1995 & 0044 & 0,0004 & 0,0004 & 0,0007 & 0,0038 & 0,0048 & 0,0022 & 0,0078 & 0,0035 & 0,0041 & 0,0173 & 0,0079 & 0,0014 & 0,059 \\
\hline 1996 & 0,0048 & 0,0073 & 0,0001 & 0,0058 & 0,0055 & 0,0039 & 0,0109 & 0,0069 & 0,0047 & 0,0043 & 0,0102 & 0,0177 & 0,0012 & 0,083 \\
\hline 1997 & 0,0110 & 0,0016 & 0,0016 & 0,0091 & 0,0040 & 0,0032 & 0,0071 & 0,0053 & 0,0104 & 0,0030 & 0,0092 & 0,0157 & 0,0010 & 0,082 \\
\hline 1998 & 0,0047 & 0,0027 & 0,0027 & 0,0008 & 0,0016 & 0,0035 & 0,0071 & 0,0106 & 0,0055 & 0,0053 & 0,0156 & 0,0232 & 0,0051 & 0,088 \\
\hline 1999 & 0,0114 & 0,0033 & 0,0038 & 0,0020 & 0,0071 & 0,0022 & 0,0023 & 0,0144 & 0,0023 & 0,0116 & 0,0086 & 0,0271 & 0,0016 & 0,098 \\
\hline 2000 & 0,0066 & 0,0023 & 0,0042 & 0,0016 & 0,0112 & 0,0035 & 0,0055 & 0,0141 & 0,0083 & 0,0148 & 0,0107 & 0,0098 & 0,0031 & 0,096 \\
\hline 2001 & 0,0056 & 0,0025 & 0,0031 & 0,0014 & 0,0020 & 0,0034 & 0,0026 & 0,0126 & 0,0095 & 0,0093 & 0,0139 & 0,0229 & 0,0025 & 0,091 \\
\hline 2002 & 0,0054 & 0,0044 & 0,0074 & 0,0011 & 0,0116 & 0,0041 & 0,0030 & 0,0075 & 0,0139 & 0,0082 & 0,0107 & 0,0233 & 0,0024 & 0,103 \\
\hline 2003 & 0,0138 & 0,0025 & 0,0083 & 0,0020 & 0,0031 & 0,0032 & 0,0045 & 0,0109 & 0,0095 & 0,0046 & 0,0128 & 0,0139 & 0,0037 & 0,093 \\
\hline 2004 & 0,0046 & & & 0,0039 & & & 0,0062 & & & & & & 0,0021 & 0,106 \\
\hline 2005 & 0,0099 & 0,0047 & 0,0075 & 0,0027 & 0,0016 & 0,0032 & 0,0054 & 0,0183 & 0,0080 & 0,0042 & 0,0023 & 0,0146 & 0,0026 & 0,085 \\
\hline 2006 & 0,0044 & 0,0026 & 0,0065 & 0,0142 & 0,0019 & 0,0036 & 0,0052 & 0,0216 & 0,0066 & 0,0061 & 0,0038 & 0,0111 & 0,0030 & 0,091 \\
\hline 2007 & 0,0063 & 0,0026 & 0,0104 & 0,0047 & 0,0027 & 0,0019 & 0,0045 & 0,0233 & 0,0063 & 0,0053 & 0,0039 & 0,0112 & 0,0033 & 0,086 \\
\hline 2008 & 0,0030 & 0,0030 & 0,0141 & 0,0046 & 0,0016 & 0,0023 & 0,0054 & 0,0126 & 0,0063 & 0,0052 & 0,0038 & 0,0125 & 0,0033 & 0,078 \\
\hline 2009 & 0,0025 & 0,0032 & 0,0090 & 0,0018 & 0,0014 & 0,0017 & 0,0041 & 0,0098 & 0,0040 & 0,0034 & & 0,0151 & & 0,068 \\
\hline 2010 & 0,0027 & 0,0033 & 0,0071 & 0,0016 & 0,0023 & 0,0016 & 0,0064 & 0,0087 & 0,0046 & 0,0041 & 0,0041 & 0,0145 & 0,0030 & 0,064 \\
\hline
\end{tabular}


Anexo 4. Municipios de Boyacá. Índices de Theil intra provincias de los Ingresos tributarios.

\begin{tabular}{|c|c|c|c|c|c|c|c|c|c|c|c|c|c|c|}
\hline Años & U⿺辶 & : & צִ & & 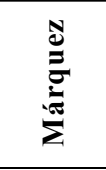 & ż & Z்̃ & 苞 & & 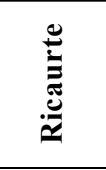 & 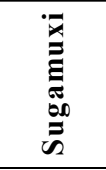 & $\begin{array}{l}\underset{\Xi}{\tilde{E}} \\
\stackrel{\Xi}{\Xi} \\
\Xi\end{array}$ & 离 & 跑 \\
\hline 1985 & 0,0312 & 0,0012 & 0,0016 & 0,0035 & 0,0015 & 0,0743 & 0,0046 & 0,0378 & 0,0129 & 0,0231 & 0,2479 & 0,0250 & 0,0074 & 0,47 \\
\hline 1986 & 0,0303 & 0,0010 & 0,0007 & 0,0018 & 0,0011 & 0,0566 & 0,0047 & 0,0386 & 0,0085 & 0,0228 & 0,2181 & 0,0266 & 0,0057 & 0,42 \\
\hline 1987 & 0,0372 & 0,0048 & 0,0011 & 0,0054 & 0,0025 & 0,0261 & 0,0024 & 0,0208 & 0,0113 & 0,0193 & 0,2612 & 0,0178 & 0,0098 & 0,42 \\
\hline 1988 & 0,0182 & 0,0023 & 0,0082 & 0,0046 & 0,0025 & 0,0060 & 0,0252 & 0,0162 & 0,0173 & 0,0281 & 0,1753 & 0,0195 & 0,0113 & 0,33 \\
\hline 1989 & 0,1566 & 0,0009 & 0,0028 & 0,0015 & 0,0021 & 0,0049 & 0,0021 & 0,0539 & 0,0096 & 0,0241 & 0,2059 & 0,0302 & 0,0141 & 0,51 \\
\hline 1990 & 0,1060 & 0,0012 & 0,0014 & 0,0007 & 0,0026 & 0,0040 & 0,0019 & 0,0398 & 0,0023 & 0,0275 & 0,2587 & 0,0330 & 0,0082 & 0,49 \\
\hline 1991 & 0,0660 & 0,0040 & 0,0025 & 0,0014 & 0,0039 & 0,0013 & 0,0056 & 0,0333 & 0,0034 & 0,0384 & 0,2582 & 0,0240 & 0,0063 & 0,45 \\
\hline 1992 & 0,0378 & 0,0024 & 0,0020 & 0,0191 & 0,0096 & 0,0010 & 0,0019 & 0,0309 & 0,0048 & 0,2073 & 0,1705 & 0,0301 & 0,0024 & 0,52 \\
\hline 1993 & 0,0633 & 0,0035 & 0,0033 & 0,0008 & 0,0099 & 0,0053 & 0,0056 & 0,0213 & 0,0046 & 0,0295 & 0,2059 & 0,0534 & 0,0030 & 0,41 \\
\hline 1994 & 0,0849 & 0,0017 & 0,0022 & 0,0007 & 0,0075 & 0,0027 & 0,0052 & 0,0173 & 0,0031 & 0,0170 & 0,0871 & 0,0451 & 0,0046 & 0,28 \\
\hline 1995 & 0,0433 & 0,0005 & 0,0010 & 0,0229 & 0,0042 & 0,0072 & 0,0029 & 0,0536 & 0,0029 & 0,0297 & 0,0866 & 0,0194 & 0,0043 & 0,28 \\
\hline 1996 & 0,0742 & 0,0012 & 0,0011 & 0,0165 & 0,0025 & 0,0042 & 0,0016 & 0,0594 & 0,0040 & 0,0196 & 0,1045 & 0,0241 & 0,0065 & 0,32 \\
\hline 1997 & 0,0602 & 0,0011 & 0,0028 & 0,0540 & 0,0081 & 0,0055 & 0,0010 & 0,0723 & 0,0043 & 0,0174 & 0,0832 & 0,0179 & 0,0020 & 0,33 \\
\hline 1998 & 0,0553 & 0,0009 & 0,0028 & 0,0711 & 0,0120 & 0,0019 & 0,0019 & 0,0759 & 0,0080 & 0,0488 & 0,0640 & 0,0136 & 0,0016 & 0,36 \\
\hline 1999 & 0,0612 & 0,0018 & 0,0022 & 0,0516 & 0,0552 & 0,0070 & 0,0016 & 0,0378 & 0,0072 & 0,0973 & 0,0439 & 0,0174 & 0,0047 & 0,39 \\
\hline 2000 & 0,0446 & 0,0012 & 0,0029 & 0,0201 & 0,0393 & 0,0067 & 0,0019 & 0,0570 & 0,0131 & 0,0261 & 0,1212 & 0,0265 & 0,0039 & 0,36 \\
\hline 2001 & 0,0388 & 0,0010 & 0,0028 & 0,0341 & 0,0237 & 0,0079 & 0,0041 & 0,0450 & 0,0283 & 0,0210 & 0,1320 & 0,0215 & 0,0026 & 0,36 \\
\hline 2002 & 0,0474 & 0,0013 & 0,0166 & 0,0223 & 0,0141 & 0,0059 & 0,0024 & 0,0432 & 0,0070 & 0,0154 & 0,1029 & 0,0280 & 0,0048 & 0,31 \\
\hline 2003 & 0,0927 & 0,0021 & 0,0219 & 0,0042 & 0,0082 & 0,0078 & 0,0022 & 0,0436 & 0,0110 & 0,0153 & 0,1155 & 0,0188 & 0,0050 & 0,35 \\
\hline 2004 & 0,0954 & 0,0038 & 0,0063 & 0,0027 & 0,0130 & 0,0059 & 0,0028 & 0,0452 & 0,0068 & 0,0119 & 0,1585 & 0,0143 & 0,0026 & 0,37 \\
\hline 2005 & 0,0897 & 0,0035 & 0,0027 & 0,0030 & 0,0037 & 0,0066 & 0,0023 & 0,0353 & 0,0051 & 0,0252 & 0,1248 & 0,0217 & 0,0035 & 0,33 \\
\hline 2006 & 0,0829 & 0,0016 & 0,0008 & 0,0043 & 0,0039 & 0,0090 & 0,0015 & 0,0263 & 0,0051 & 0,0345 & 0,1357 & 0,0152 & 0,0042 & 0,33 \\
\hline 2007 & 0,0541 & 0,0008 & 0,0079 & 0,0063 & 0,0080 & 0,0177 & 0,0018 & 0,0222 & 0,0036 & 0,0347 & 0,0784 & 0,0140 & 0,0054 & 0,25 \\
\hline 2008 & 0,0492 & 0,0009 & 0,0022 & 0,0099 & 0,0064 & 0,0069 & 0,0031 & 0,0227 & 0,0042 & 0,0246 & 0,1004 & 0,0183 & 0,0066 & 0,26 \\
\hline 2009 & 0,0335 & 0,0011 & 0,0050 & 0,0073 & 0,0036 & 0,0055 & 0,0017 & 0,0166 & 0,0027 & 0,0234 & 0,1148 & 0,0141 & 0,0061 & 0,24 \\
\hline 2010 & 0,0292 & 0,0009 & 0,0044 & 0,0074 & 0,0075 & 0,0053 & 0,0039 & 0,0136 & 0,0036 & 0,0210 & 0,0947 & 0,0149 & 0,0076 & 0,21 \\
\hline
\end{tabular}

Fuente: cálculos del autor con base en las ejecuciones presupuestales del DNP, varios años. 
Anexo 5. Municipios de Boyacá. Índices de Theil intra provincias del Ingreso Predial.

\begin{tabular}{|c|c|c|c|c|c|c|c|c|c|c|c|c|c|c|}
\hline Años & U⿺辶大 & نू. & צִ & 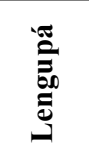 & 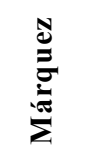 & Z & $\begin{array}{l}\stackrel{0}{0} \\
\dot{0}\end{array}$ & 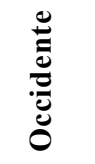 & 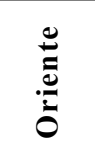 & 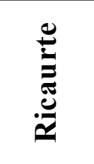 & 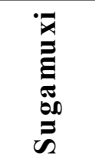 & 舃 & 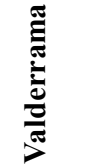 & 焉焉 \\
\hline 1985 & 0,016 & 0,002 & 0,002 & 0,004 & 0,001 & 0,137 & 0,008 & 0,055 & 0,004 & 0,013 & 0,039 & 0,010 & 0,006 & 0,30 \\
\hline 1986 & 0,013 & 0,002 & 0,001 & 0,002 & 0,002 & 0,103 & 0,008 & 0,044 & 0,004 & 0,011 & 0,036 & 0,012 & 0,005 & 0,24 \\
\hline 1987 & 0,019 & 0,004 & 0,001 & 0,003 & 0,003 & 0,065 & 0,002 & 0,014 & 0,005 & 0,015 & 0,032 & 0,028 & 0,003 & 0,19 \\
\hline 1988 & 0,010 & 0,004 & 0,001 & 0,011 & 0,005 & 0,002 & 0,002 & 0,037 & 0,034 & 0,066 & 0,050 & 0,024 & 0,007 & 0,25 \\
\hline 1989 & 0,014 & 0,001 & 0,001 & 0,003 & 0,002 & 0,003 & 0,002 & 0,066 & 0,005 & 0,028 & 0,061 & 0,018 & 0,005 & 0,21 \\
\hline 1990 & 0,015 & 0,001 & 0,000 & 0,001 & 0,003 & 0,004 & 0,004 & 0,061 & $-0,002$ & 0,036 & 0,060 & 0,023 & 0,004 & 0,21 \\
\hline 1991 & 0,014 & 0,005 & 0,005 & 0,001 & 0,008 & 0,011 & 0,010 & 0,059 & 0,003 & 0,021 & 0,055 & 0,014 & 0,002 & 0,21 \\
\hline 1992 & 0,021 & 0,003 & 0,004 & 0,000 & 0,020 & 0,008 & 0,003 & 0,037 & 0,006 & 0,032 & 0,023 & 0,026 & 0,003 & 0,19 \\
\hline 1993 & 0,018 & 0,005 & 0,005 & 0,001 & 0,015 & 0,008 & 0,009 & 0,033 & 0,006 & 0,021 & 0,107 & 0,022 & 0,004 & 0,25 \\
\hline 1994 & 0,030 & 0,002 & 0,003 & 0,001 & 0,011 & 0,009 & 0,008 & 0,025 & 0,009 & 0,018 & 0,021 & 0,019 & 0,004 & 0,16 \\
\hline 1995 & 0,022 & 0,001 & 0,002 & 0,000 & 0,007 & 0,001 & 0,005 & 0,036 & 0,002 & 0,035 & 0,051 & 0,012 & 0,006 & 0,18 \\
\hline 1996 & 0,028 & 0,002 & 0,001 & 0,000 & 0,004 & 0,002 & 0,003 & 0,092 & 0,006 & 0,023 & 0,031 & 0,012 & 0,009 & 0,21 \\
\hline 1997 & 0,029 & 0,002 & 0,001 & 0,000 & 0,004 & 0,005 & 0,002 & 0,119 & 0,007 & 0,023 & 0,027 & 0,013 & 0,002 & 0,23 \\
\hline 1998 & 0,029 & 0,002 & 0,001 & 0,004 & 0,004 & 0,002 & 0,003 & 0,143 & 0,008 & 0,019 & 0,027 & 0,010 & 0,002 & 0,25 \\
\hline 1999 & 0,025 & 0,004 & 0,001 & 0,002 & 0,004 & 0,001 & 0,003 & 0,085 & 0,010 & 0,032 & 0,029 & 0,013 & 0,005 & 0,22 \\
\hline 2000 & 0,024 & 0,002 & 0,001 & 0,001 & 0,004 & 0,002 & 0,003 & 0,117 & 0,006 & 0,023 & 0,030 & 0,015 & 0,002 & 0,228 \\
\hline 2001 & 0,022 & 0,001 & 0,001 & 0,001 & 0,002 & 0,004 & 0,004 & 0,099 & 0,030 & 0,017 & 0,024 & 0,018 & 0,001 & 0,23 \\
\hline 2002 & 0,029 & 0,002 & 0,001 & 0,002 & 0,011 & 0,001 & 0,003 & 0,127 & 0,006 & 0,021 & 0,025 & 0,025 & 0,008 & 0,26 \\
\hline 2003 & 0,034 & 0,002 & 0,001 & 0,000 & 0,002 & 0,002 & 0,003 & 0,124 & 0,016 & 0,021 & 0,045 & 0,012 & 0,005 & 0,27 \\
\hline 2004 & 0,024 & 0,003 & 0,002 & 0,003 & 0,009 & 0,004 & 0,005 & 0,134 & 0,003 & 0,013 & 0,033 & 0,011 & 0,002 & 0,24 \\
\hline 2005 & 0,030 & 0,002 & 0,001 & 0,002 & 0,004 & 0,003 & 0,004 & 0,113 & 0,003 & 0,027 & 0,032 & 0,021 & 0,002 & 0,24 \\
\hline 2006 & 0,037 & 0,002 & 0,003 & 0,003 & 0,001 & 0,005 & 0,003 & 0,089 & 0,003 & 0,032 & 0,031 & 0,013 & 0,004 & 0,23 \\
\hline 2007 & 0,034 & 0,002 & 0,004 & 0,002 & 0,002 & 0,004 & 0,002 & 0,090 & 0,003 & 0,028 & 0,026 & 0,013 & 0,003 & 0,21 \\
\hline 2008 & 0,032 & 0,002 & 0,003 & 0,001 & 0,003 & 0,005 & 0,002 & 0,092 & 0,002 & 0,026 & 0,050 & 0,015 & 0,006 & 0,24 \\
\hline 2009 & 0,030 & 0,002 & 0,002 & 0,002 & 0,003 & 0,005 & 0,001 & 0,075 & 0,004 & 0,027 & 0,055 & 0,016 & 0,006 & 0,23 \\
\hline 2010 & 0,032 & 0,002 & 0,003 & 0,006 & 0,003 & 0,005 & 0,002 & 0,081 & 0,004 & 0,028 & 0,041 & 0,016 & 0,010 & 0,23 \\
\hline
\end{tabular}


Anexo 6. Municipios de Boyacá. Índices de Theil intra provincias del ICA.

\begin{tabular}{|c|c|c|c|c|c|c|c|c|c|c|c|c|c|c|}
\hline Años & ن⿺辶 & قِّ & צ & 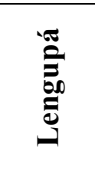 & 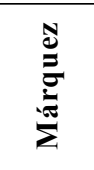 & $\frac{\pi}{\tilde{J}}$ & 苛 & & 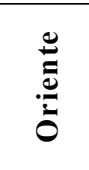 & 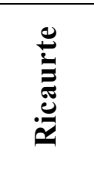 & 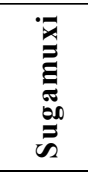 & 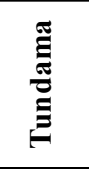 & & 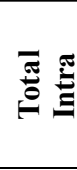 \\
\hline 1985 & 0,036 & 0,000 & 0,000 & 0,000 & 0,000 & 0,101 & 0,000 & 0,017 & 0,027 & 0,037 & 0,504 & 0,045 & 0,009 & 0,63 \\
\hline 1986 & 0,031 & 0,000 & 0,000 & 0,001 & 0,003 & 0,089 & 0,000 & 0,013 & 0,011 & 0,050 & 0,485 & 0,043 & 0,005 & 0,60 \\
\hline 1987 & 0,084 & 0,000 & 0,000 & 0,000 & 0,001 & 0,045 & 0,002 & 0,001 & 0,012 & 0,038 & 0,566 & 0,014 & 0,031 & 0,66 \\
\hline 1988 & 0,060 & 0,005 & 0,005 & 0,011 & 0,000 & 0,037 & 0,006 & 0,010 & 0,018 & 0,030 & 0,549 & 0,064 & 0,043 & 0,66 \\
\hline 1989 & 0,436 & 0,000 & 0,000 & 0,001 & 0,002 & 0,029 & 0,004 & 0,020 & 0,006 & 0,018 & 0,454 & 0,043 & 0,038 & 0,74 \\
\hline 1990 & 0,354 & 0,002 & 0,001 & 0,001 & 0,002 & 0,033 & 0,001 & 0,025 & 0,015 & 0,020 & 0,618 & 0,073 & 0,041 & 0,80 \\
\hline 1991 & 0,261 & 0,001 & 0,001 & 0,008 & 0,002 & 0,060 & 0,002 & 0,021 & 0,020 & 0,045 & 0,610 & 0,059 & 0,030 & 0,78 \\
\hline 1992 & 0,186 & 0,002 & 0,001 & 0,001 & 0,001 & 0,067 & 0,001 & 0,034 & 0,016 & 0,019 & 0,599 & 0,127 & 0,004 & 0,75 \\
\hline 1993 & 0,235 & 0,001 & 0,001 & 0,003 & 0,002 & 0,079 & 0,000 & 0,025 & 0,020 & 0,054 & 0,462 & 0,186 & 0,004 & 0,72 \\
\hline 1994 & 0,327 & 0,004 & 0,001 & 0,003 & 0,003 & 0,087 & 0,002 & 0,026 & 0,022 & 0,026 & 0,385 & 0,150 & 0,014 & 0,71 \\
\hline 1995 & 0,266 & 0,001 & 0,010 & 0,006 & 0,004 & 0,097 & 0,004 & 0,038 & 0,020 & 0,041 & 0,344 & 0,051 & 0,003 & 0,64 \\
\hline 1996 & 0,322 & 0,000 & 0,007 & 0,051 & 0,003 & 0,065 & 0,002 & 0,026 & 0,013 & 0,023 & 0,381 & 0,065 & 0,006 & 0,68 \\
\hline 1997 & 0,192 & 0,000 & 0,009 & 0,238 & 0,039 & 0,048 & 0,001 & 0,022 & 0,009 & 0,047 & 0,200 & 0,031 & 0,003 & 0,60 \\
\hline 1998 & 0,223 & 0,001 & 0,008 & 0,369 & 0,003 & 0,055 & 0,000 & 0,025 & 0,015 & 0,009 & 0,160 & 0,031 & 0,004 & 0,65 \\
\hline 1999 & 0,204 & 0,004 & 0,004 & 0,266 & 0,001 & 0,086 & 0,000 & 0,034 & 0,020 & 0,023 & 0,174 & 0,060 & 0,005 & 0,62 \\
\hline 2000 & 0,146 & 0,003 & 0,018 & 0,146 & 0,004 & 0,066 & 0,001 & 0,023 & 0,013 & 0,014 & 0,407 & 0,056 & 0,004 & 0,65 \\
\hline 2001 & 0,084 & 0,003 & 0,003 & 0,137 & 0,002 & 0,075 & 0,009 & 0,018 & 0,026 & 0,008 & 0,438 & 0,043 & 0,004 & 0,63 \\
\hline 2002 & 0,145 & 0,002 & 0,062 & 0,076 & 0,007 & 0,045 & 0,005 & 0,012 & 0,009 & 0,007 & 0,350 & 0,028 & 0,003 & 0,57 \\
\hline 2003 & 0,338 & 0,001 & 0,088 & 0,005 & 0,003 & 0,044 & 0,004 & 0,013 & 0,012 & 0,009 & 0,328 & 0,026 & 0,002 & 0,64 \\
\hline 2004 & 0,335 & 0,001 & 0,028 & 0,004 & 0,002 & 0,040 & 0,002 & 0,035 & 0,009 & 0,007 & 0,449 & 0,030 & 0,007 & 0,69 \\
\hline 2005 & 0,338 & 0,001 & 0,004 & 0,002 & 0,003 & 0,033 & 0,003 & 0,015 & 0,009 & 0,011 & 0,422 & 0,037 & 0,010 & 0,66 \\
\hline 2006 & 0,288 & 0,002 & 0,001 & 0,008 & 0,003 & 0,040 & 0,005 & 0,012 & 0,008 & 0,011 & 0,415 & 0,020 & 0,012 & 0,63 \\
\hline 2007 & 0,200 & 0,001 & 0,003 & 0,010 & 0,005 & 0,093 & 0,001 & 0,016 & 0,007 & 0,015 & 0,289 & 0,037 & 0,010 & 0,54 \\
\hline 2008 & 0,199 & 0,003 & 0,006 & 0,003 & 0,004 & 0,041 & 0,020 & 0,014 & 0,010 & 0,008 & 0,371 & 0,043 & 0,009 & 0,57 \\
\hline 2009 & 0,122 & 0,001 & 0,008 & 0,005 & 0,002 & 0,037 & 0,014 & 0,015 & 0,005 & 0,007 & 0,397 & 0,021 & 0,009 & 0,53 \\
\hline 2010 & 0,123 & 0,001 & 0,019 & 0,012 & 0,003 & 0,030 & 0,003 & 0,011 & 0,006 & 0,008 & 0,354 & 0,032 & 0,012 & 0,51 \\
\hline
\end{tabular}

Fuente: cálculos del autor con base en las ejecuciones presupuestales del DNP, varios años. 